\section{(6) OPEN ACCESS}

\title{
Liver PPAR $\alpha$ is crucial for whole-body fatty acid homeostasis and is protective against NAFLD
}

\author{
Alexandra Montagner, ${ }_{1}^{1}$ Arnaud Polizzi, ${ }_{1}^{1}$ Edwin Fouché, ${ }^{1}$ Simon Ducheix, ${ }_{1}$ \\ Yannick Lippi, ${ }^{1}$ Frédéric Lasserre, ${ }^{1}$ Valentin Barquissau, ${ }^{2,3}$ Marion Régnier, ${ }^{1}$ \\ Céline Lukowicz, ${ }^{1}$ Fadila Benhamed, ${ }^{4,5,6}$ Alison Iroz, ${ }^{4,5,6}$ Justine Bertrand-Michel, ${ }^{2,3}$ \\ Talal Al Saati, ${ }^{7}$ Patricia Cano, ${ }^{1}$ Laila Mselli-Lakhal, ${ }^{1}$ Gilles Mithieux, ${ }^{8}$ Fabienne Rajas, ${ }^{8}$ \\ Sandrine Lagarrigue, ${ }^{9,10,11}$ Thierry Pineau, ${ }^{1}$ Nicolas Loiseau, ${ }_{1}^{1}$ Catherine Postic, ${ }^{4,5,6}$ \\ Dominique Langin, ${ }^{2,3,12}$ Walter Wahli, ${ }^{1,13,14}$ Hervé Guillou $^{{ }^{1}}$
}

\begin{abstract}
- Additional material is published online only. To view please visit the journal online (http://dx.doi.org/10.1136/ gutjnl-2015-310798).

For numbered affiliations see end of article.

Correspondence to Dr Hervé Guillou, INRA UMR1331, ToxAlim,

Chemin de Tournefeuille, Toulouse 31027, France: herve.guillou@toulouse.inra.fr or

Prof. Walter Wahli Lee Kong Chian School of Medicine Nanyang Technological University The Academia, 20 College Road, Singapore 169856;

walter.wahli@ntu.edu.sg
\end{abstract}

Received 25 September 2015 Revised 28 December 2015 Accepted 4 January 2016 Published Online First 2 February 2016

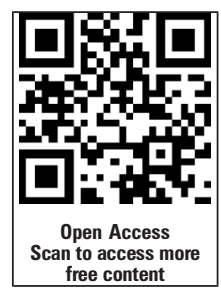

\section{SLinked}

- http://dx.doi.org/10.1136/ gutjnl-2016-311408

\section{CrossMark}

To cite: Montagner $A$ Polizzi A, Fouché $E$, et al. Gut 2016;65:1202-1214.

\section{ABSTRACT}

Objective Peroxisome proliferator-activated receptor $\alpha$ (PPAR $\alpha$ ) is a nuclear receptor expressed in tissues with high oxidative activity that plays a central role in metabolism. In this work, we investigated the effect of hepatocyte PPAR $\alpha$ on non-alcoholic fatty liver disease (NAFLD).

Design We constructed a novel hepatocyte-specific PPAR $\alpha$ knockout $\left(P p a r \alpha^{\text {hep-l-}}{ }^{-}\right)$mouse model. Using this novel model, we performed transcriptomic analysis following fenofibrate treatment. Next, we investigated which physiological challenges impact on PPAR $\alpha$. Moreover, we measured the contribution of hepatocytic PPAR $\alpha$ activity to whole-body metabolism and fibroblast growth factor 21 production during fasting. Finally, we determined the influence of hepatocyte-specific PPAR $\alpha$ deficiency in different models of steatosis and during ageing.

Results Hepatocyte PPAR $\alpha$ deletion impaired fatty acid catabolism, resulting in hepatic lipid accumulation during fasting and in two preclinical models of steatosis. Fasting mice showed acute PPAR $\alpha$-dependent hepatocyte activity during early night, with correspondingly increased circulating free fatty acids, which could be further stimulated by adipocyte lipolysis. Fasting led to mild hypoglycaemia and hypothermia in Ppara $\alpha^{\text {hep-l- }}$ mice when compared with $P_{p a r \alpha^{-1-}}$ mice implying a role of PPAR $\alpha$ activity in non-hepatic tissues. In agreement with this observation, Ppar $\alpha^{-1-}$ mice became overweight during ageing while $P$ para ${ }^{\text {hep-l- }}$ remained lean. However, like Ppara ${ }^{-l-}$ mice, Ppara ${ }^{\text {hep-l- }}$ fed a standard diet developed hepatic steatosis in ageing. Conclusions Altogether, these findings underscore the potential of hepatocyte PPAR $\alpha$ as a drug target for NAFLD.

\section{INTRODUCTION}

Precise control of fatty acid metabolism is essential. Defective fatty acid homeostasis regulation may induce lipotoxic tissue damage, including hepatic steatosis. ${ }^{1}$ Peroxisome proliferator-activated receptors (PPARs) are transcription factors that serve as fatty acid receptors and help regulate gene expression in response to fatty acid-derived stimuli. ${ }^{2}$ PPARs act as ligand-activated receptors, controlling

\section{Significance of this study}

What is already known on this subject?

- Peroxisome proliferator-activated receptor $\alpha$ (PPAR $\alpha$ ) is a nuclear receptor expressed in many tissues and is responsible for several important metabolic controls, especially during fasting.

- PPAR $\alpha$ is a target for the hypolipidemic drugs of the fibrate family.

- PPAR $\alpha$ is less expressed in the liver of patients with non-alcoholic fatty liver diseases (NAFLD).

- Several PPAR-targeting molecules, including dual agonists, are currently under investigation for NAFLD treatment.

What are the new findings?

- Hepatocyte-restricted PPAR $\alpha$ deletion impairs liver and whole-body fatty acid homeostasis.

- Hepatic PPAR $\alpha$ responds to acute and chronic adipose tissue lipolysis.

- Hepatic PPAR $\alpha$ regulates circadian fibroblast growth factor 21 (FGF21) and fasting-induced FGF21, and is partially responsible for the FGF21 increase in steatohepatitis.

- Hepatocyte-restricted PPAR $\alpha$ deletion is sufficient to promote NAFLD and hypercholesterolaemia during ageing, but does not lead mice to become overweight.

How might it impact on clinical practice in the foreseeable future?

- This work emphasises the relevance and potential of hepatic PPAR $\alpha$ as a drug target for NAFLD.

target gene transcription. The three PPAR isotypes, PPAR $\alpha, P P A R \beta / \delta$ and PPAR $\gamma$, display specific tissue expression patterns and control different biological functions, ${ }^{3}$ but all bind lipids and control lipid homeostasis in different tissues, including the liver. ${ }^{2}$

A healthy liver does not accumulate lipids, but it plays central roles in fatty acid anabolism and export to peripheral organs, including white 
adipose tissue for energy storage. ${ }^{4}$ During dietary restriction, hepatic fatty acid catabolism is also critical for using free fatty acids (FFAs) released from white adipose tissues. PPAR $\alpha$ is the most abundant isotype in hepatocytes and is involved in many aspects of lipid metabolism, ${ }^{56}$ including fatty acid degradation, synthesis, transport, storage, lipoprotein metabolism and ketogenesis during fasting. ${ }^{7-9}$ In addition, PPAR $\alpha$ controls glycerol use for gluconeogenesis ${ }^{9}$ as well as autophagy ${ }^{10}$ in response to fasting. Moreover, PPAR $\alpha$ regulates the expression of the fibroblast growth factor 21 (FGF21) during starvation. ${ }^{11}{ }^{12}$ In turn, FGF21 acts as an endocrine hormone targeting various functions including metabolic control. ${ }^{13}$ Finally, PPAR $\alpha$ helps repress the acute-phase response and inflammation in the liver. ${ }^{14}$

Obesity can lead to organ and vascular complications. ${ }^{15}$ Non-alcoholic fatty liver disease (NAFLD), which are considered the hepatic manifestation of metabolic syndrome, range from benign steatosis to severe non-alcoholic steatohepatitis (NASH), potentially further damaging organs. ${ }^{16}$ Sustained elevation of neutral lipid accumulation (mostly triglycerides in hepatocyte lipid droplets) initiates early pathological stages. Different fatty acid sources contribute to fatty liver development, including dietary lipid intake, de novo lipogenesis and adipose tissue lipolysis. ${ }^{4}$ In NAFLD, $60 \%$ of fatty acids accumulated in steatotic liver are adipose-derived. ${ }^{17}$

Preclinical ${ }^{18-21}$ and clinical $^{22}$ studies highlight that PPAR $\alpha$ influences NAFLD and NASH. Mice lacking PPAR $\alpha$ develop steatosis during fasting, ${ }^{78}$ suggesting the importance of PPAR $\alpha$ activity for using FFA released from adipocytes. However, PPAR $\alpha$ is expressed and active in many tissues, including skeletal muscles, ${ }^{23}$ adipose tissues, ${ }^{24} 25$ intestines, ${ }^{26}$ kidneys $^{27}$ and heart, ${ }^{28}$ which all contribute to fatty acid homeostasis. Therefore, it remains unknown whether the increased steatosis susceptibility in mice lacking PPAR $\alpha$ depends on PPAR $\alpha$ activity only in hepatocytes or also in other organs.

Here we investigated consequences of hepatocyte-specific Ppara deletion, focusing on effects on fatty acid metabolism in NAFLD, ranging from steatosis to steatohepatitis. We report the first evidence that adipocyte lipolysis correlates with and stimulates NAFLD when hepatocytes are lacking PPAR $\alpha$. Our data establish that hepatocyte-restricted Ppar $\alpha$ deletion is sufficient to promote steatosis, emphasising this receptor's relevance as a drug target in NAFLD.

\section{MATERIALS AND METHODS \\ Animals}

Generation of floxed-Ppara mice and of Ppara hepatocytespecific knockout (Ppard ${ }^{\text {hep-l-}}$ ) animals is described in online supplementary file 1 .

\section{In vivo experiments}

In vivo studies followed the European Union guidelines for laboratory animal use and care, and were approved by an independent ethics committee.

Detailed experimental protocols are provided in online supplementary file 1.

\section{Plasma analysis}

Plasma FGF21 and insulin, respectively, were assayed using the rat/mouse FGF21 ELISA kit (EMD Millipore) and the ultrasensitive mouse insulin ELISA kit (Crystal Chem) following the manufacturer's instructions. Aspartate transaminase, alanine transaminase (ALT), total cholesterol, LDL cholesterol and HDL cholesterol were determined using a COBAS-MIRA+ biochemical analyser (Anexplo facility).

\section{Circulating glucose and ketone bodies}

Blood glucose was measured using an Accu-Chek Go glucometer (Roche Diagnostics). $\beta$-Hydroxybutyrate content was measured using Optium $\beta$-ketone test strips with Optium Xceed sensors (Abbott Diabetes Care).

\section{Histology}

Paraformaldehyde-fixed, paraffin-embedded liver tissue was sliced into $5 \mu \mathrm{m}$ sections and H\&E stained. Visualisation was performed using a Leica DFC300 camera.

\section{Liver lipids analysis}

Detailed experimental protocols are provided in online supplementary file 1 .

\section{Gene expression studies}

Total RNA was extracted with TRIzol reagent (Invitrogen). Transcriptomic profiles were obtained using Agilent Whole Mouse Genome microarrays $(4 \times 44 \mathrm{k})$. Microarray data and experimental details are available in the Gene Expression Omnibus (GEO) database (accession number GSE73298 and GSE73299). For real-time quantitative PCR (qPCR), $2 \mu \mathrm{g}$ RNA samples were reverse-transcribed using the High-Capacity cDNA Reverse Transcription Kit (Applied Biosystems). Online supplementary file 2 presents the SYBR Green assay primers. Amplifications were performed using an ABI Prism 7300 Real-Time PCR System (Applied Biosystems). qPCR data were normalised to TATA-box-binding protein mRNA levels, and analysed with LinRegPCR.v2015.3.

\section{Transcriptomic data analysis}

Data were analysed using $\mathrm{R}$ (http://www.r-project.org). Microarray data were processed using Bioconductor packages

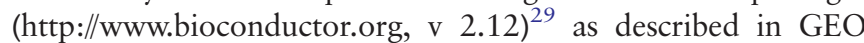
entry GSE26728. Further details are provided in online supplementary file 1 .

\section{Statistical analysis}

Data were analysed using $\mathrm{R}$ (http://www.r-project.org). Microarray data were processed using bioconductor packages (http://www.bioconductor.org) as described in GEO entry GSE38083. Genes with a q value of $<0.001$ were considered differentially expressed between genotypes. Gene Ontology (GO) Biological Process enrichment was evaluated using conditional hypergeometric tests (GOstats package). For nonmicroarray data, differential effects were analysed by analysis of variance followed by Student's t-tests with a pooled variance estimate. A $p$ value $<0.05$ was considered significant.

\section{RESULTS}

\section{Generation of hepatocyte-specific PPAR $\alpha$ knockout mice}

Progeny carrying the Ppara flox/flox alleles (figure 1A), referred to as floxed, were backcrossed in the $\mathrm{C} 57 \mathrm{Bl} / 6 \mathrm{~J}$ background, and then crossed with albumin-Cre mice in the same genetic background, generating a hepatocyte-specific PPAR $\alpha$ knockout (Ppard ${ }^{\text {flox/flox }}$ albumin-Cre ${ }^{+-}$) referred to as Ppard $\alpha^{\text {hep-l- }}$ (figure 1B). PPAR $\alpha$ mRNA was not detected in livers from Ppara $^{\text {hep-I- }}$ mice when compared with floxed and C57B16/J mice (figure 1C), suggesting that most hepatic PPAR $\alpha$ expression is from hepatocytes. PPAR $\alpha$ absence in hepatocytes did not alter mRNA expression of other PPAR isotypes (figure 1C). 
Figure 1 Characterisation of the hepatocyte-specific peroxisome proliferator-activated receptor $\alpha$ (PPAR $\alpha$ ) knockout mouse model. (A) Schematic of the targeting strategy to disrupt hepatic Ppara expression. (B) PCR analysis of Ppara floxed (Ppard hep ${ }^{+/+}$) and Albumin-Cre (Albumin-Cre ${ }^{+/-}$) genes from mice that are liver wild-type (WT), (Ppard $\left.{ }^{\text {hep+/++}}\right)$ or liver knockout $\left(\right.$ Ppard $\left.^{\text {hep-l-}}\right)$ for Ppar $\alpha$ using DNA extracted from different organs. (C) Relative mRNA expression levels of Ppar $\alpha, P$ par $\beta / \delta$ and Ppar $\gamma$ from liver samples of WT, liver WT $\left(\right.$ Ppard $\left.{ }^{h e p+/+}\right)$, Pparo liver knockout (Ppard $^{\text {hep-/-) }}$ ) and Ppara knockout $\left(\right.$ Ppar $\left.^{-1-}\right)$ mice ( $\mathrm{n}=8$ mice per group). Data represent mean \pm SEM. ${ }^{* * *} p \leq 0.005$. FA, floxed allele; Flp, flippase; FRT, flippase recognition target; LoxP, locus of X-overP1; nd, not detected; Ppar $\alpha \Delta$, Ppar $\alpha$ deletion; WT, the Albumin-Cre ${ }^{-I-}$ allele.

A Exon [ FRT \ LoxP

Wild-type allele

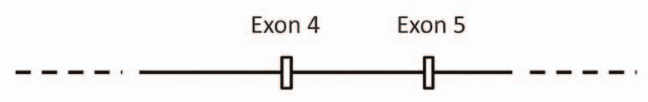

Targeting vector

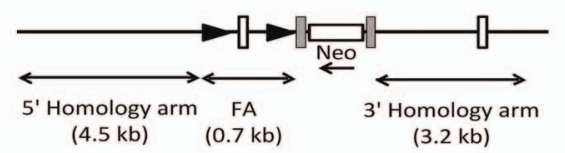

Targeted allele

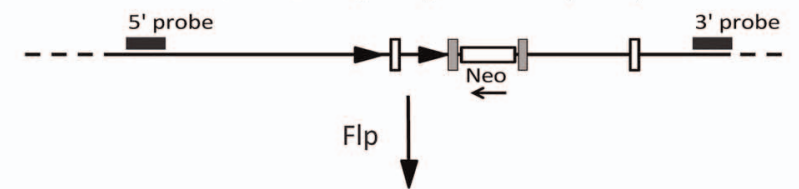

Floxed allele

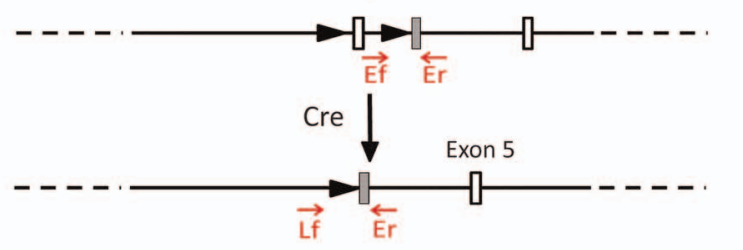

Null allele

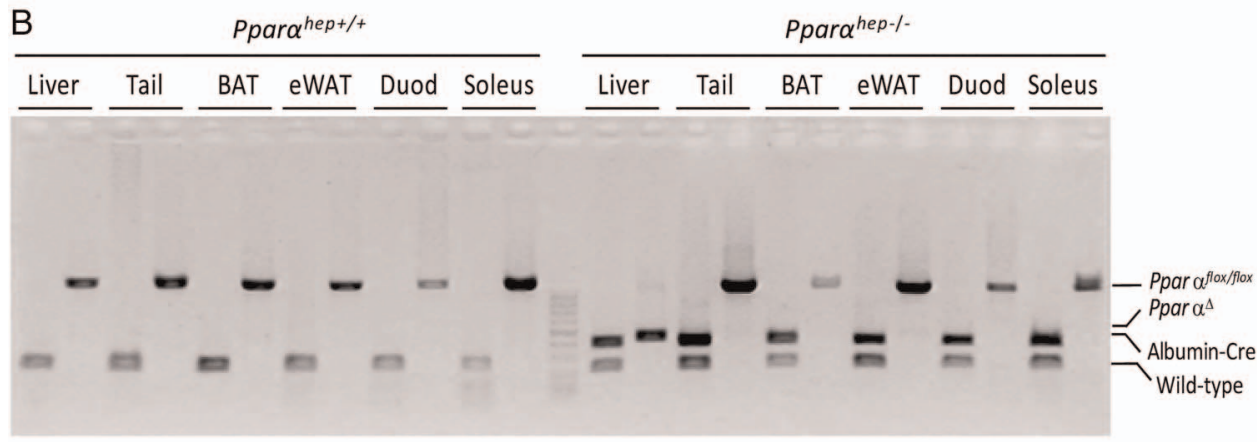

C

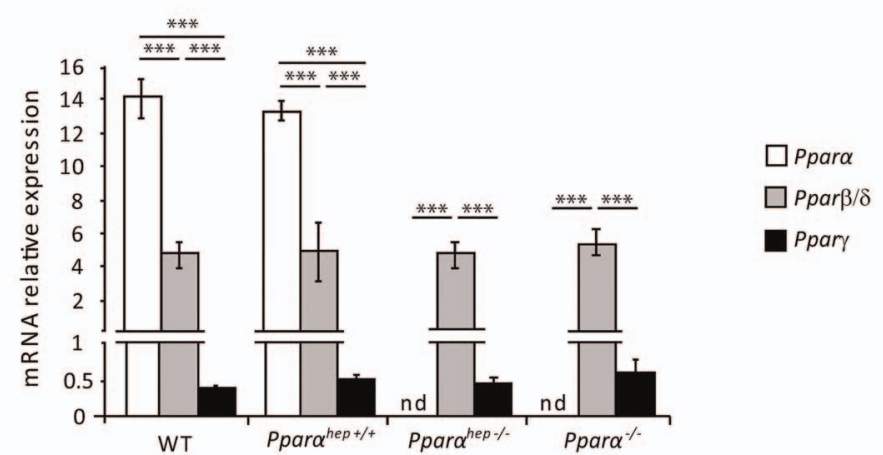

\section{Hepatocyte-autonomous effect of fenofibrate on PPAR $\alpha$ activity}

To determine whether PPAR $\alpha$ response was hepatocyte-autonomous, we challenged wild-type (WT), floxed

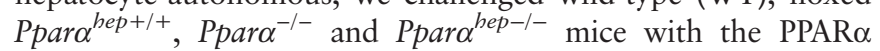
agonist fenofibrate. We measured mRNA expressions of PPAR $\alpha$ target genes, including Cyp4a10 (figure 2A) and Cyp4a14 (figure 2B). Their expressions were strongly induced by fenofibrate in WT and in floxed Ppard ${ }^{\text {hep+/+ }}$ mice compared with Ppara $^{-/-}$and Pparo ${ }^{\text {hep-l- }}$ mice. These samples were also used for pangenomic expression profiling through microarray analysis (figure 2C). Differentially expressed gene (DEG) analysis was subjected to hierarchical clustering, highlighting similar expression profiles between WT and floxed Ppard ${ }^{\text {hep }+/+}$ mice within fenofibrate-treated or vehicle-treated groups. Whole-body

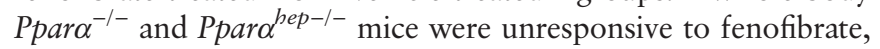
suggesting that fenofibrate-induced hepatic changes were mainly due to autonomous hepatocyte responses, not secondary to extrahepatic PPAR $\alpha$ activation. GO biological function analysis revealed that fenofibrate upregulated lipid metabolism, and repressed immune and defence response, metabolic responses, and glycosylation and glycoprotein metabolism (figure 2C, groups 1, 2, 6 and 7). However, untreated Pparo $^{-/-}$and Ppard ${ }^{\text {hep-l- }}$ mice showed marked differences (figure 2C, groups 3, 4, 8 and 9). This implies that the absence of extrahepatic PPAR $\alpha$ has a significant impact on the liver transcriptional profile and underscores the relevance of Ppara ${ }^{\text {hep-l- }}$ mice to define the hepatocyte autonomous role of the receptor in the control of liver function.

\section{Hepatocyte PPARo activity is context-specific}

The Ppard ${ }^{\text {hep-l- }}$ model was used to determine whether PPAR $\alpha$ could drive hepatic regulations both in fasting-induced fatty acid catabolism as well as fatty acid anabolism during refeeding. The 
A

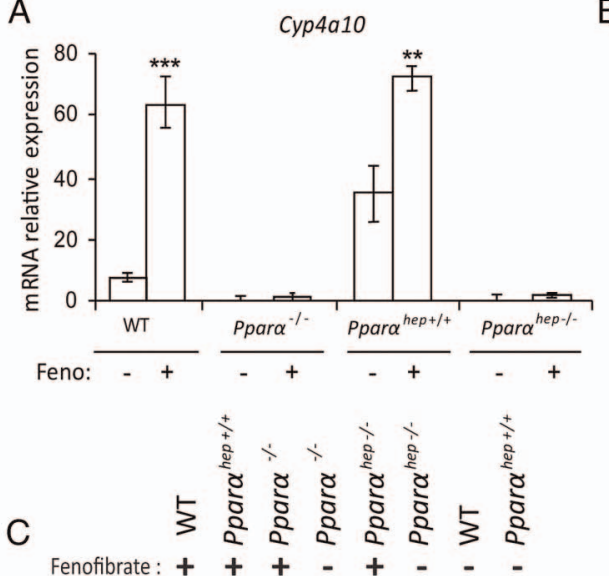

B

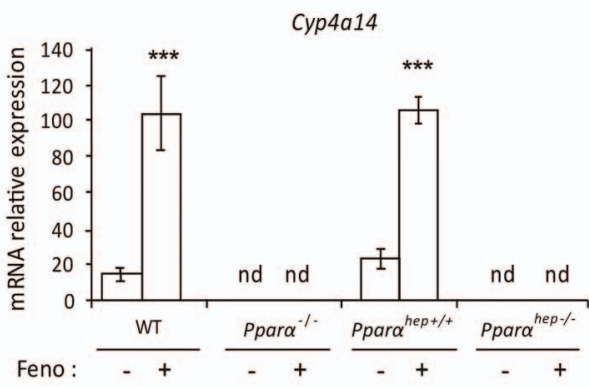

Figure 2 Pharmacological peroxisome proliferator-activated receptor $\alpha$ (PPAR $\alpha$ ) activation using fenofibrate reveals hepatocyte-specific PPAR $\alpha$-dependent biological functions. Liver samples from wild-type (WT), PPAR $\alpha$ knockout $\left(P p a r \alpha^{-1-}\right)$, liver WT $\left(P p a r \alpha^{\text {hep+/++}}\right)$ and Ppar $\alpha$ hepatocyte knockout $\left(\right.$ Ppard $\left.^{\text {hep-l-}}\right)$ mice treated with fenofibrate $(F e n o,+)$ or vehicle $(-)$ by oral gavage for 14 days were collected. (A and B) The relative gene expression of two specific PPAR $\alpha$ target genes Cyp4a10 (A) and Cyp4a14 (B) was measured by qRT-PCR. Data represent mean \pm SEM. ${ }^{* *} p \leq 0.01,{ }^{* * *} p \leq 0.005$. (C) Heat map representing data from a microarray experiment performed with liver samples. Hierarchical clustering is also shown, which allows the definition of nine gene clusters. Gene Ontology (GO) analysis of each cluster revealed significant biological functions $(p \leq 0.05)$. nd, not detected.

fasting-refeeding experimental design was validated by measuring glycaemia (figure 3A) and expression of fatty acid synthase (Fasn), which encodes the rate-limiting enzyme in lipogenesis (figure 3B). Both were low during fasting, intermediary in ad libitum-fed animals, and high in refed animals. Cyp4a14 (a wellknown PPAR $\alpha$ target) expression was low or undetectable in Pparo ${ }^{\text {hep-l- }}$ animals, and strongly upregulated with fasting in WT mice (figure 3C).
Next we evaluated the hepatic transcriptome expression pattern using microarrays. We performed hierarchical clustering (figure 3D). Most PPAR $\alpha$-dependent changes were observed in fasted mouse livers. Venn diagrams were used to show nutritional status-related PPAR $\alpha$-dependent changes (figure 3E). Among the significant DEGs, 3048 were related to fasting, 390 to ad libitum-fed animals and 156 to refed mice, suggesting context-specific PPAR $\alpha$ activity. The results further highlighted 
A

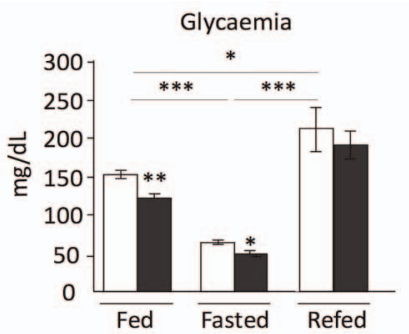

B

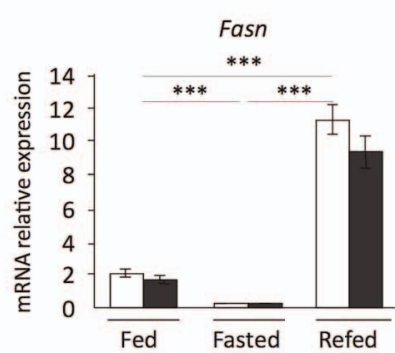

C

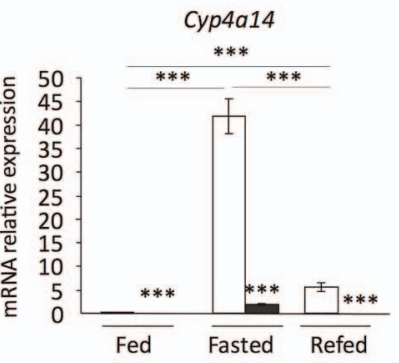

E

FED group

$1 \mathrm{GO}$ category up in Ppard ${ }^{\text {hep } \%}$

1 'acute-phase response'

10 GO categories down in Ppara ${ }^{\text {hep- }}$ including:

6 related to catabolism / oxidation

3 related to metabolism

REFED group

3 GO categories up in Ppard ${ }^{\text {hep- }- \text { : }}$

1 'alcohol metabolic process'

1 'organic substance biosynthetic process'

1 'translation'

10 GO categories down in Ppard ${ }^{\text {hep- }}$ including:

7 related to catabolism / oxidation

3 related to metabolism
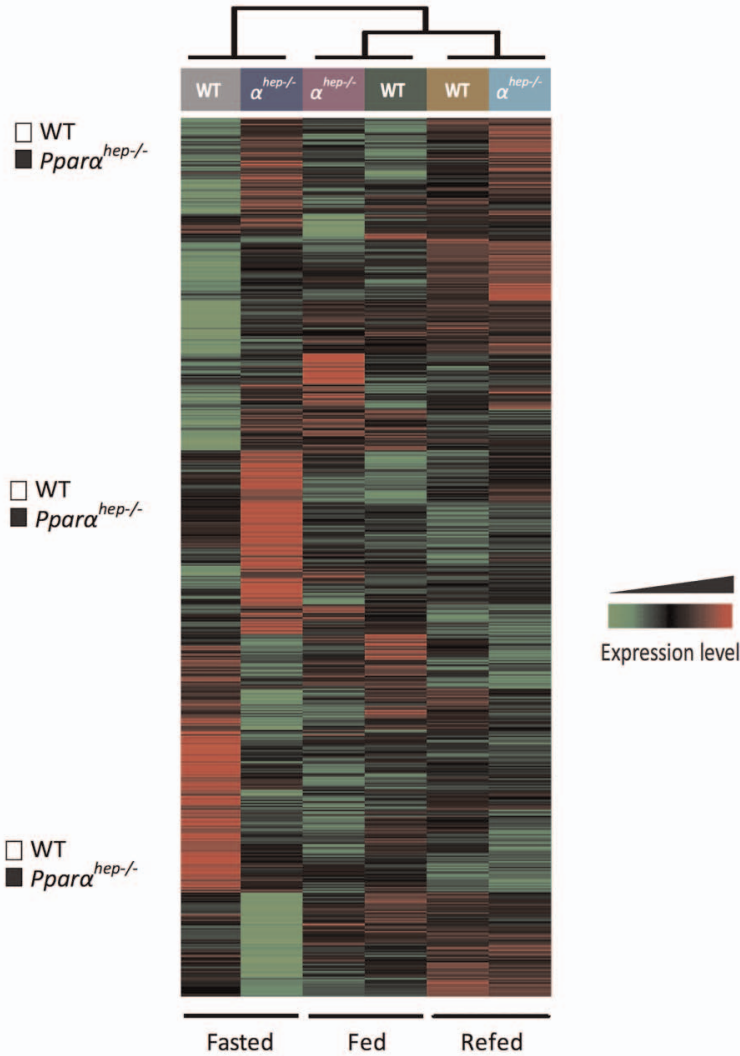

Expression level

\section{FASTED group}

15 GO categories up in Ppard ${ }^{\text {hep } /-}$ including:

6 related to nucleotide metabolism

4 related to immune response

2 related to ER protein catabolism

and Unfolded Protein Response

1 'protein $\mathrm{N}$-linked glycosylation

via asparagine'

48 GO categories down in Ppard ${ }^{\text {hep- }-1}$ including:

24 related to metabolism

13 related to catabolism / oxidation

4 related to ATP / mitochondria

2 related to transport /localization

1 'peroxisome organisation'

Figure 3 Hepatocyte-specific peroxisome proliferator-activated receptor $\alpha$ (PPAR $\alpha$ ) function is dependent on nutritional status. Wild-type (WT) and PPAR $\alpha$ liver knockout (Ppard ${ }^{\text {hep-l--}}$ ) male 8-week-old mice were fed ad libitum, fasted for $24 \mathrm{~h}$, or fasted for $24 \mathrm{~h}$ and refed for $24 \mathrm{~h}$. All mice were killed at ZT14, and sera and livers were collected. (A) Quantification of circulating glucose levels. (B, C) Relative mRNA expressions of Fasn (B) and Cyp4a14 (C) in liver samples quantified by qRT-PCR. Data represent mean \pm SEM. ${ }^{*} p \leq 0.05,{ }^{*} p \leq 0.01,{ }^{*}{ }^{*} p \leq 0.005$. (D) Heat map was performed based on average gene expression levels from WT ( $n=12$ (6 WT and 6 Ppard $\left.\left.{ }^{\text {hep+/++}}\right)\right)$ and from Ppard ${ }^{\text {hep-/- }}(\mathrm{n}=6)$. (E) Venn diagram and associated Gene Ontology (GO) function analysis ( $\mathrm{p} \leq 0.05)$, GO categories corresponding to functions down in the absence of PPAR $\alpha$ are in bold, GO categories corresponding to functions up in the absence of PPAR $\alpha$ are in regular font.

that fasting, rather than feeding or refeeding, triggered the broader PPAR $\alpha$-dependent hepatocytic response, with most upregulated genes related to metabolism (figure $3 \mathrm{E}$ ). However, the expression of several genes was identified as PPAR $\alpha$ dependent regardless of the nutritional condition tested (fasting, but also feeding and refeeding). These genes are mostly downregulated in the absence of PPAR $\alpha$ and pathway analysis highlights their involvement in mitochondrial fatty acid catabolism (see online supplementary file 3).

Biological function analyses revealed that both transcriptional activation and repression were PPAR $\alpha$ sensitive (figure $3 \mathrm{E}$ ). The functions of PPAR $\alpha$-sensitive repressions (GO categories up in Ppara ${ }^{\text {hep-l- }}$ mice) varied with context, and included GO categories not directly related to metabolism, including acute-phase 
response (fed), translation (refed) and protein glycosylation (fasted).

\section{Hepatocyte PPAR $\alpha$ is required for liver and whole-body fatty acid homeostasis in fasting}

We next used Ppard ${ }^{\text {hep-I- }}$ mice to determine the contribution of hepatocyte PPAR $\alpha$, and compared it with Ppara ${ }^{-/}$and WT mice. We measured FFA and $\beta$-hydroxybutyrate (ketonaemia) levels in fasted and non-fasted mice (figure 4A). Plasma FFA was elevated in fasting mice of all three genotypes, but was significantly higher in Ppard ${ }^{\text {hep-I- }}$ and Ppard ${ }^{-/-}$mice compared with controls. Fasting strongly increased ketone body levels in WT mice and to a lesser degree in Ppard ${ }^{\text {hep-l- }}$ and Ppara ${ }^{-/}$mice. This suggests that hepatic PPAR $\alpha$ is required for FFA disposal and for $\beta$-hydroxybutyrate production. Correspondingly, fasting Pparo $^{\text {hep-I- }}$ and Ppara ${ }^{-/-}$mice showed elevated hepatic triglycerides and cholesterol esters (figure 4B), and substantial centrilobular steatosis (figure 4C), confirming that hepatic PPAR $\alpha$ expression is required for fasting-induced FFA catabolism. PPAR $\alpha$ absence led to defective expressions of PPAR $\alpha$ target genes (figure 4D), including those involved in fatty acid catabolism and processing in lipid droplets (figure 4E). As a consequence of PPAR $\alpha$ deficiency in hepatocytes, Pparo $\alpha^{\text {hep-l- }}$ mice exhibit a distinct fasting-induced fatty acid profile with a significant increase in oleic acid (C18:1n-9) and linoleic acid (C18:2n-6) when compared with WT mice (see online supplementary file 4).

\section{Hepatocyte-specific Ppar $\alpha$ deletion impairs constitutive and fasting-induced FGF21 expression}

FGF21 is a hepatokine mainly produced by the liver. We examined liver Fgf21 mRNA expression (figure 5A) and plasma FGF21 levels (figure 5B) in fed and fasted animals. We identified a constitutive expression peak during the day (ZT8) in both groups, and a fasting-triggered night-time peak (ZT16). In Ppard $^{\text {hep-l- }}$ mice, we examined whether fasting-induced FGF21 expression/production was strictly dependent on PPAR $\alpha$ hepatic activity. Ppara ${ }^{-/-}$and Ppard ${ }^{\text {hep-l- }}$ mice showed very low plasma FGF21 protein at ZT8 or at ZT16 with fasting (figure 5C).

Since FGF21 has been shown to reduce steatosis and lipotoxic lipids ${ }^{13} 30$ we questioned whether the absence of FGF21 determines fasting-induced steatosis observed in Ppara ${ }^{\text {hep-I- }}$ and Ppara ${ }^{-/}$mice. FGF21 expression was rescued by adenoviral delivery both in Ppard ${ }^{\text {hep-I- }}$ and in Pparo ${ }^{-/}$mice (figure 5D). Comparable expression of FGF21 (figure 5E) was obtained in liver of WT, Ppard ${ }^{\text {hep-l- }}$ and in Ppard ${ }^{-/-}$mice. FGF21-sensitive genes such as G6pd and $S c d 1$ showed significantly different expression in response to FGF21 overexpression (figure 5E). However, FGF21 only reduced hepatic triglycerides and cholesterol esters in WT mice, but not in Ppard hep-I- $^{\text {and in Ppara }}{ }^{--}$ mice (figure 5F, G). These results indicate that the fasting-induced steatosis occurring in Pparo ${ }^{\text {hep-I- }}$ and in Ppara ${ }^{-1}$ mice does not depend on the lack of FGF21. This is in line with our observations that FGF21- and PPAR $\alpha$-sensitive target genes are different (see online supplementary file 5A). Moreover, it is also consistent with the observation that FGF21 overexpression does not rescue the expression of PPAR $\alpha$ target genes and conversely that PPAR $\alpha$-sensitive regulations occur in F $22^{-1-}$ mice (see online supplementary file 5B, C).

In addition to their defective fatty acid catabolism, $\mathrm{Ppard}^{-/-}$ mice are hypoglycaemic and hypothermic during fasting. ${ }^{7}$ Because FGF21 is important for glucose homeostasis and for thermogenesis, ${ }^{13}$ we investigated the role of hepatocyte PPAR $\alpha$ in controlling fasting glycaemia and body temperature. Both
Ppara ${ }^{\text {hep-I- }}$ and Ppara ${ }^{-/}$mice were hypoglycaemic and hypothermic compared with WT mice during fasting. However, this phenotype was much stronger in fasted Ppara ${ }^{-/-}$mice compared with fasted Ppard ${ }^{\text {hep-I- }}$ mice (figure $5 \mathrm{H}-\mathrm{J}$ ), indicating that extrahepatic PPAR $\alpha$ strongly influenced whole-body glucose homeostasis and temperature independent of hepatocytic PPAR $\alpha$ activity and FGF21 production.

\section{Fasting-enhanced hepatocytic PPAR $\alpha$ activity is time-restricted and sensitive to adipocyte lipolysis}

We next tested the kinetics of other fasting-induced hepatic PPAR $\alpha$ activity in vivo. We used several measures of PPARo activity, including Fgf21 (figure 5A) and Vanin1, Cyp4a10, Cyp4a14 and Fsp27 mRNAs (figure 6A), since these genes were most sensitive to fasting and to fenofibrate, and were strictly PPAR $\alpha$ dependent (see online supplementary files 6-10A). Plasma FFA and glucose levels were also measured during fasting (figure 6B). FFA were markedly increased in the early night (ZT14-ZT16). The FFA pattern was correlated with the PPAR $\alpha$ mRNA expression profile and expressions of Fgf21, Vanin1, Cyp4a10, Cyp4a14 and Fsp27 (figures 5A and 6A). This strongly suggested that FFA released from adipocytes during fasting-influenced hepatic PPAR $\alpha$ expression and activity without inflammatory response since hepatic Tnfo mRNA expression was not sensitive to fasting. We further determined that acute treatment of fasted mice with the $\beta 3$-adrenergic receptor agonist CL316243 enhanced circulating FFA levels in WT and Ppara ${ }^{\text {hep-l- }}$ mice (figure $6 \mathrm{C}$ ), and increased expressions of Fgf21, Cyp4a14, Vanin1, Cyp4a10 and Fsp27 in WT mice but not Ppar $\alpha^{\text {hep-l- }}$ mice (figure 6D) without inducing Tnf $\alpha$ in response to fasting or in response to CL316243 (see online supplementary file 10C and D). These data support a role for acute adipocyte lipolysis as a signal for hepatocyte PPAR $\alpha$ activity during fasting.

\section{Hepatocyte PPARa is required for protection in steatohepatitis}

We next examined whether the hepatocytic PPAR $\alpha$ response to chronic lipolysis occurred during methionine-deficient and choline-deficient diet (MCD)-induced weight loss. In rodents, this diet rapidly promotes lipolysis in adipocytes, resulting in steatohepatitis. On the MCD diet, mice of each genotype showed weight loss (figure 7A), steatosis (figure 7B), and increased hepatic triglycerides, cholesterol esters (figure 7C) and plasma ALT (figure 7D). Compared with WT, Ppard ${ }^{\text {hep-I- }}$ and $\mathrm{Ppard}^{-/-}$mice showed greater steatosis and liver damage, suggesting a more severe MCD diet-induced phenotype without hepatocyte PPAR $\alpha$. MCD also induced increased expressions of Cyp4a14 and Vanin1 in WT mice, but not Ppard ${ }^{\text {hep-l- }}$ or Ppara $^{-1-}$ mice (figure 7E). Fgf21 mRNA (figure 7E) and circulating FGF21 (figure 7F) were increased through a mechanism that is partly dependent on hepatic PPAR $\alpha$. Overall, hepatocytespecific Ppara deletion aggravated MCD diet-induced liver damage, correlating with defective PPAR $\alpha$-dependent pathway upregulation in response to chronic lipolysis.

Additionally, we questioned whether hepatocyte PPAR $\alpha$ may also be required for the protection of the liver during early hits in steatosis such as those occurring in response to short-term exposure to a high-fat diet (HFD). Over 2 weeks of HFD, mouse liver accumulated hepatic triglycerides and cholesterol esters. Importantly, this steatosis was twice higher in Ppard ${ }^{\text {hep-I- }}$ mice than in WT mice, and was further elevated in Ppara ${ }^{-1}$ mice (see online supplementary file 11). Altogether, these data suggest that hepatic PPAR $\alpha$ is essential in hepatoprotection. 
A

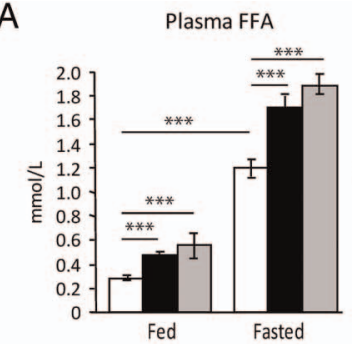

C

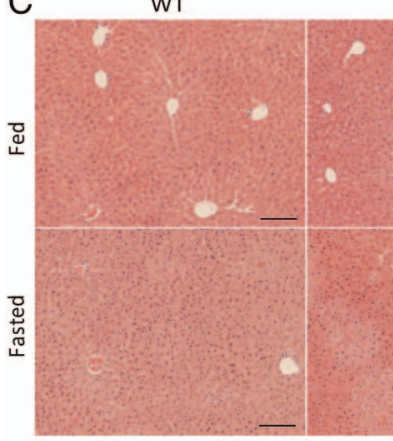

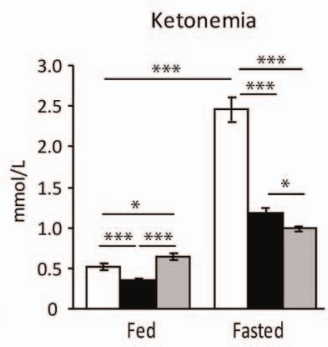

Ppara ${ }^{\text {hep }}$.
B

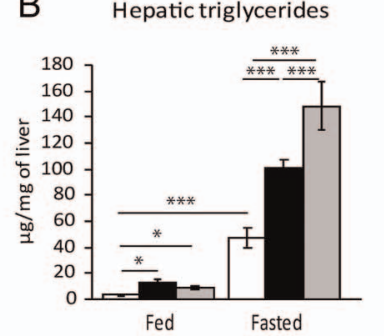

$\mathrm{D}$

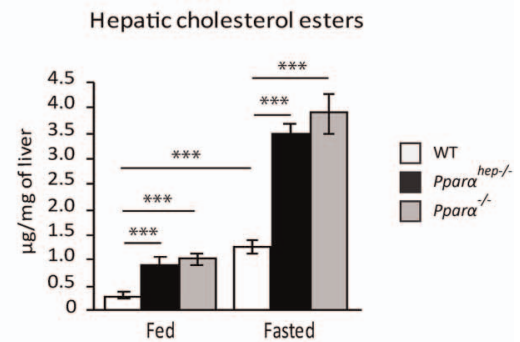

Ppara ${ }^{-1-}$

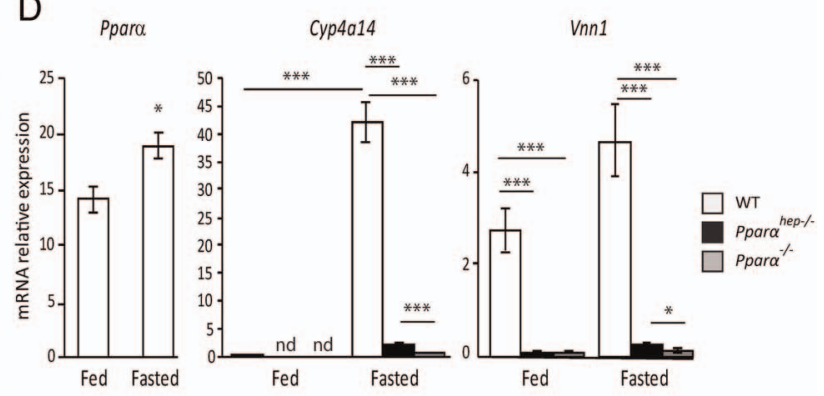

E
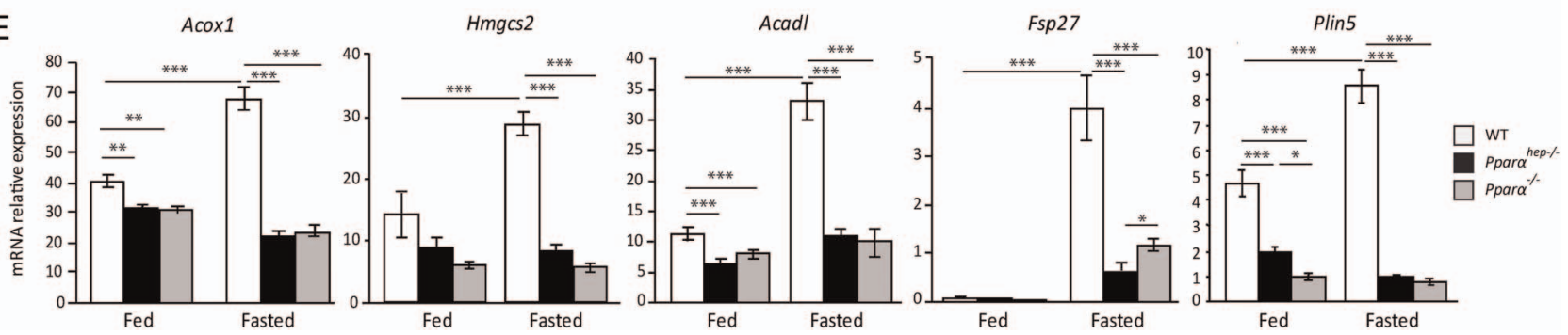

Figure 4 Fasting is the major inducer of hepatic peroxisome proliferator-activated receptor $\alpha$ (PPAR $\alpha$ ) activity. Wild-type (WT), hepatocyte-specific PPAR $\alpha$ knockout $\left(P p a r \alpha^{\text {hep-- }}-\right)$ and total PPAR $\alpha$ knockout $\left(P p a r \alpha^{-/-}\right)$mice were fed ad libitum or fasted for $24 \mathrm{~h}$ and then killed. (A) Quantification of plasma free fatty acids (FFAs) and ketone bodies (ketonaemia). (B) Hepatic triglycerides and cholesterol esters hepatic levels. (C) Representative pictures of H\&E staining of liver sections. Scale bars, $100 \mu \mathrm{m}$. (D) Relative mRNA expression levels of Ppar ${ }_{1}$ Cyp4a14 and Vnn1 in liver samples determined by qRT-PCR. (E) Quantification of mRNA expression of Acox1, Hmgcs2, Acadl, Fsp27 and Plin5 by qRT-PCR. Data shown as mean \pm SEM. ${ }^{*} \mathrm{p} \leq 0.05,{ }^{* *} \mathrm{p} \leq 0.01,{ }^{* * *} \mathrm{p} \leq 0.005$.

\section{Hepatocyte PPAR $\alpha$ deficiency leads to steatosis and hypercholesterolaemia but not excess weight gain in ageing mice}

Lastly, we questioned the long-term consequences of hepatocyte-specific Ppara deletion during ageing. More specifically, since PPAR $\alpha$ is broadly expressed in metabolic tissues, we aimed at clarifying whether the steatosis that develops in aged whole-body Ppara ${ }^{-/-}$mice is due to the hepatocytic defect in PPAR $\alpha$ activity. WT, Ppard ${ }^{\text {hep-l- }}$ and Ppara ${ }^{-/-}$mice were fed a standard diet over 1 year. Ppara ${ }^{-/-}$mice, but not Ppard ${ }^{\text {hep-I- }}$ mice, grew overweight with ageing (figure $8 \mathrm{~A}-\mathrm{C}$ ). Both Ppard ${ }^{\text {hep }}$ -/- and Ppara ${ }^{-/-}$mice showed spontaneous centrilobular steatosis (figure 8D), elevated hepatic triglycerides and hepatic cholesterol esters (figure 8E), as well as hypercholesterolaemia (see figure $8 \mathrm{~F}$ online supplementary file 12 ) without hyperglycaemia (figure 8G). Overall, hepatocyte-specific PPAR $\alpha$ deficiency was sufficient to induce spontaneous steatosis and disrupt wholebody fatty acid as well as cholesterol homeostasis, but did not affect weight gain and diabetes during ageing.

\section{DISCUSSION}

NAFLD are a spectrum of diseases presenting a major public health concern that is strongly linked with obesity. Most accumulated hepatic fatty acids in NAFLD come from increased non-esterified FFA in the fasting state. ${ }^{17}$ Thus, it is essential to define the mechanisms by which the liver adapts to this influx. FFA processing largely involves the fatty acid oxidative pathway, coupled to ketogenesis allowing the liver to use lipids, ${ }^{31}$ which is critical during fasting and requires transcriptional regulation of rate-limiting enzymes. ${ }^{32}$

Whole-body Ppard ${ }^{-/-}$mice show impaired coping with prolonged fasting, resulting in defective fatty acid oxidation and steatosis, hypoglycaemia and hypothermia. However, PPAR $\alpha$ also contributes to metabolic homeostasis through expression in other tissues. Here we investigated the impact of hepatocytespecific PPAR $\alpha$ deletion on liver physiology and lipid metabolism in vivo. To our knowledge, this is the first report that selective PPAR $\alpha$ deletion in hepatocytes $\left(\right.$ Ppard $^{\text {hep-l-}}$ ) was sufficient to promote hepatic steatosis.

PPAR $\alpha$ is targeted by several fibrate drugs, ${ }^{33}$ and by pan-agonists for PPAR isotypes ${ }^{21}$ that are currently in clinical trials for NASH treatment. Using Ppard ${ }^{\text {hep-l- }}$ mice, we demonstrated an autonomous transcriptional response of hepatocytes to fenofibrate, indicating that fibrates' effects on the liver gene expression are largely independent from those in extrahepatic tissues. Moreover, liver gene expression profiles markedly differed between untreated Ppar $^{-/-}$and Ppard ${ }^{\text {hep-l- }}$ mice, suggesting that extrahepatocytic PPAR $\alpha$ activity substantially influenced the hepatic transcriptome.

Food restriction induces PPAR $\alpha$ activity, and endogenous PPAR $\alpha$ ligand production requires hepatic lipogenesis, which 

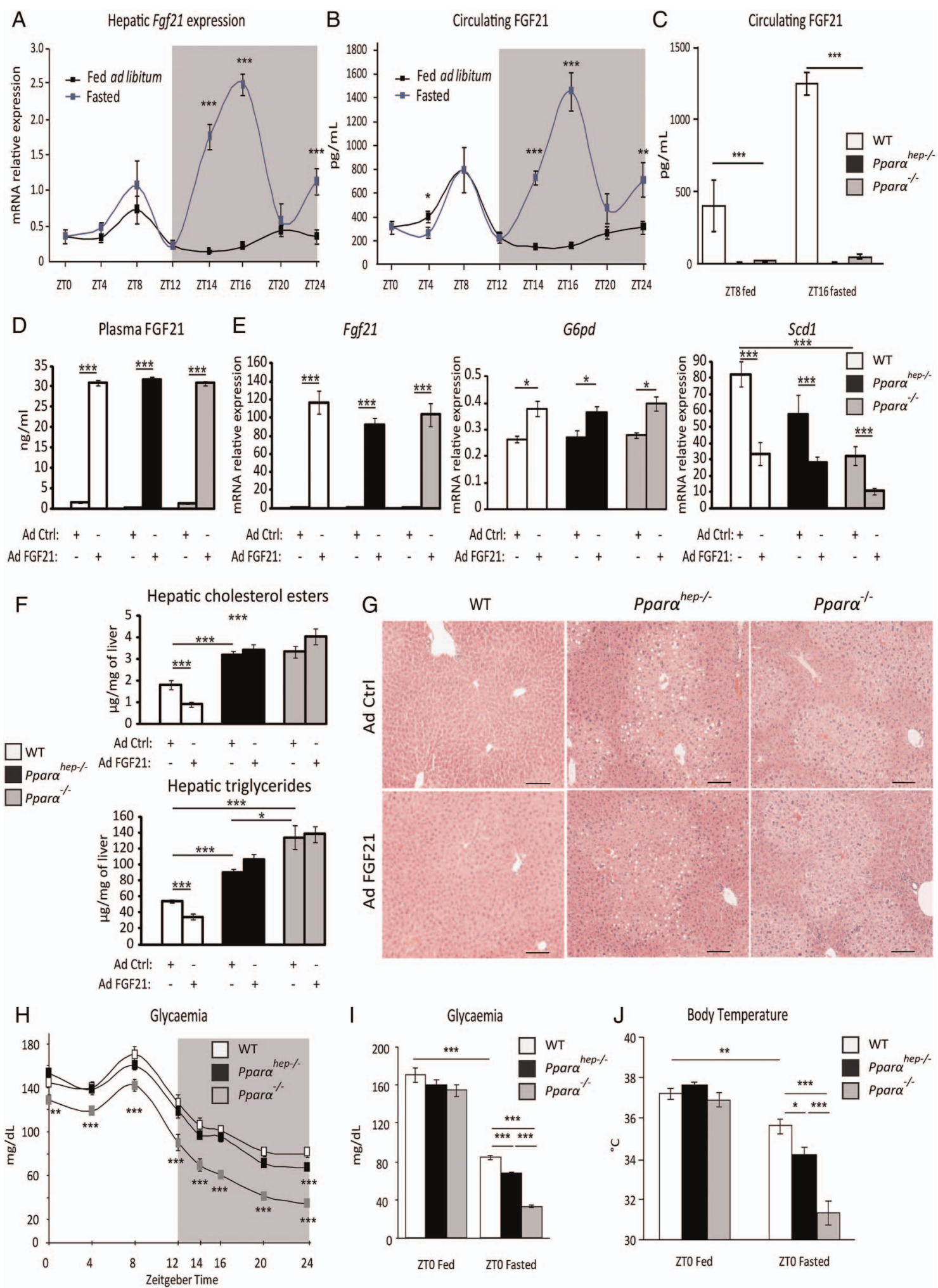

Figure 5 Hepatocyte and extrahepatocyte peroxisome proliferator-activated receptor $\alpha$ (PPAR $\alpha$ ) regulate fibroblast growth factor 21 (FGF21), glycaemia and body temperature during fasting. (A and B) Eleven-week-old male mice of the C57Bl/6J background were fed ad libitum or fasted for $24 \mathrm{~h}$, and were killed around the clock from ZT0 to ZT24. (A) Fgf21 mRNA was quantified by qRT-PCR. (B) Quantification of circulating FGF21 levels by ELISA. (C) Twelve-week-old wild-type (WT), PPAR $\alpha$-hepatocyte knockout $\left(P p a r \alpha^{\text {hep---}}\right)$ and PPAR $\alpha$ knockout $\left(P p a r \alpha^{-1-}\right)$ male mice were fed ad libitum or fasted for $16 \mathrm{~h}$ and blood was collected at ZT8 (ZT8 fed) or at ZT16 (ZT16 fasted). FGF21 plasma level was determined by ELISA. (D-G) Male mice of WT, Ppard ${ }^{\text {hep-I- }}$ and Ppard ${ }^{-/}$genotypes were infected with an adenoviral construct containing CDNA of Fgf21 or an empty vector. Mice were sacrificed after a $24 \mathrm{~h}$ fasting period at ZT14. (D) Quantification of circulating FGF21 levels by ELISA. (E) Fgf21, G6pd and Scd1 mRNAs were quantified by qRT-PCR. (F) Quantification of hepatic cholesterol esters and triglycerides. (G) Representative pictures of H\&E staining of liver sections. Scale bars, $100 \mu \mathrm{m}$. (H) Plasma glucose level was monitored over a $24 \mathrm{~h}$ fasting period from ZTO to ZT24 in WT, Pparo ${ }^{\text {hep }-1-}$ and Ppara ${ }^{-1-}$ mice. (I, J) Plasma glucose (I) and body temperature (J) were determined at ZTO in fed mice or at ZTO in mice fasted for $24 \mathrm{~h}$. Data are shown as mean \pm SEM. ${ }^{*} p \leq 0.05,{ }^{*} p \leq 0.01,{ }^{* * *} p \leq 0.005$. 
A
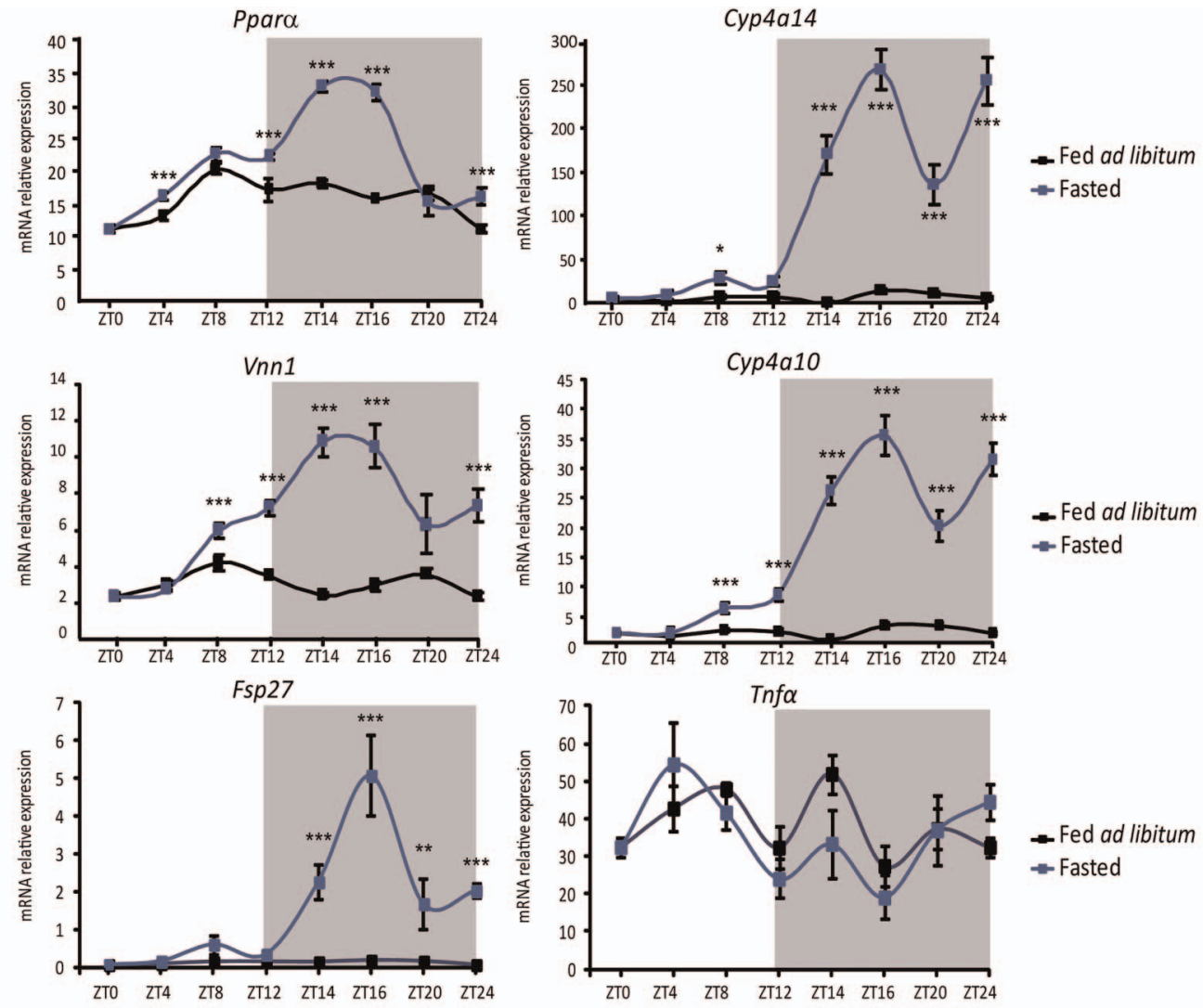

B
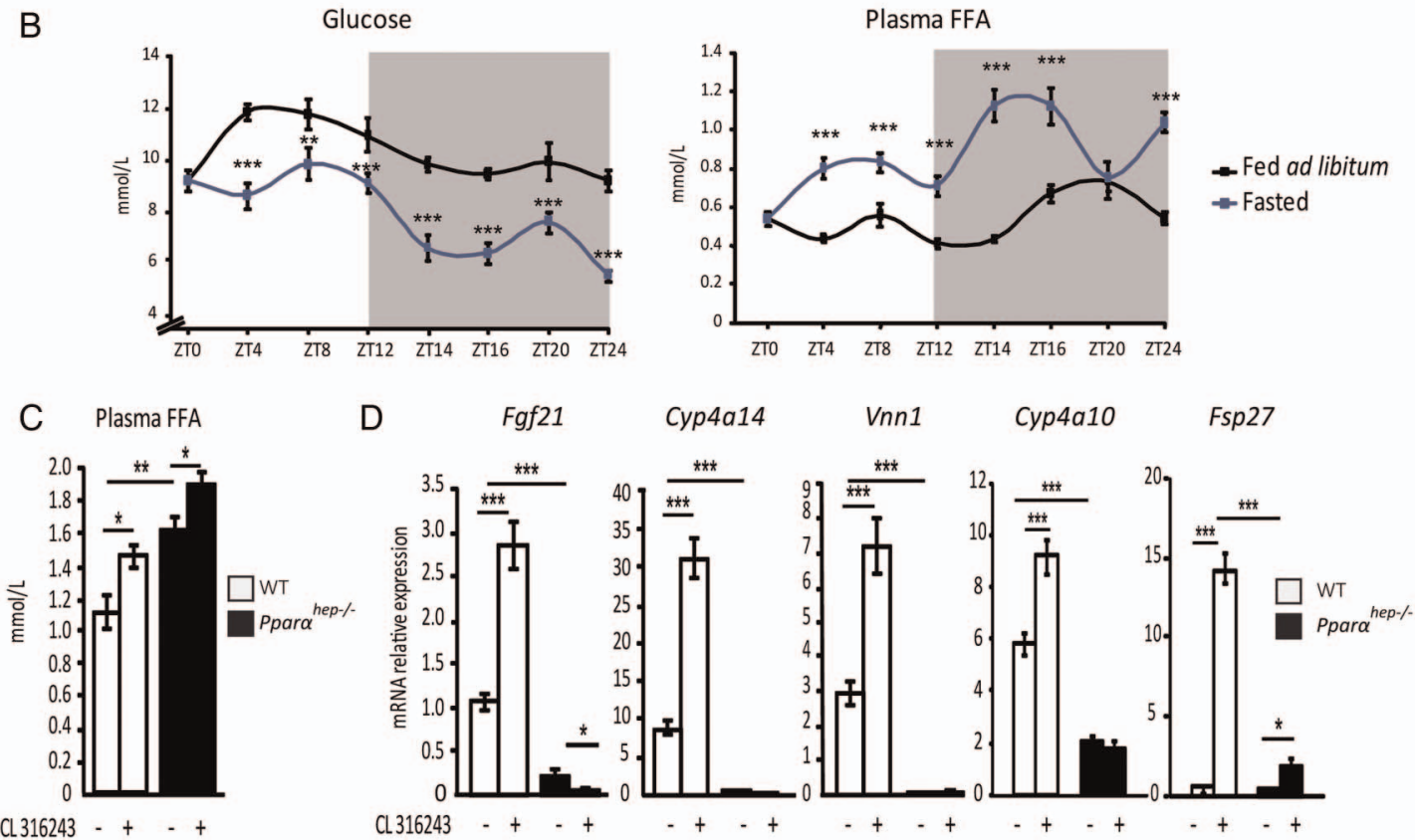

Figure 6 Hepatocyte peroxisome proliferator-activated receptor $\alpha$ (PPAR $\alpha$ ) activity is induced by adipose tissue lipolysis. (A and B) Liver samples were collected from male wild-type (WT) C57BI/6J mice that were fed ad libitum (black curve) or fasted (blue curve) over $24 \mathrm{~h}$. (A) Hepatic mRNA expression levels of Pparo, Cyp4a14, Vnn1, Cyp4a10, Fsp27 and Tnf $\alpha$ were quantified by qRT-PCR. (B) Plasma glucose and free fatty acids (FFA) were measured. (C and D) WT and PPAR $\alpha$ hepatocyte-specific knockout (Ppar ${ }^{\text {hep-l-}}$ ) mice were treated with the $\beta 3$-adrenergic receptor agonist CL316243 at ZT6 and then killed at ZT14. (C) Quantification of plasma FFA. (D) Relative mRNA expression levels of Fgf21, Cyp4a14, Vnn1, Cyp4a10 and Fsp27 were measured by qRT-PCR. Data are shown as mean \pm SEM. ${ }^{*} \mathrm{p} \leq 0.05,{ }^{* *} \mathrm{p} \leq 0.01,{ }^{* * *} \mathrm{p} \leq 0.005$.

increases upon feeding. ${ }^{34} 35$ Thus, PPAR $\alpha$ may be important during fasting-induced lipid catabolism and in the response to anabolic fatty acid-derived signals. Our data revealed the context dependency of PPAR $\alpha$ hepatocytic activity defined by DEGs. This activity was clearly the highest during fasting.
During fasting, hepatocyte-specific PPAR $\alpha$ deletion resulted in steatosis, increased plasma FFA and impaired ketone bodies. This supports the concept that FFA released from adipose stores during fasting may activate PPAR $\alpha$ for hepatic use. Accordingly, we found that Ppard ${ }^{\text {hep-l- }}$ mice accumulate high oleic and 
A

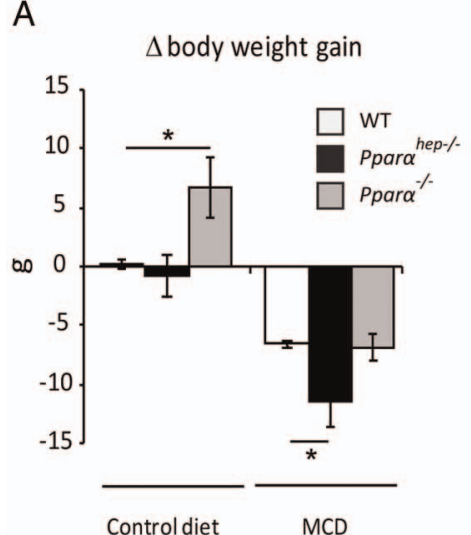

C

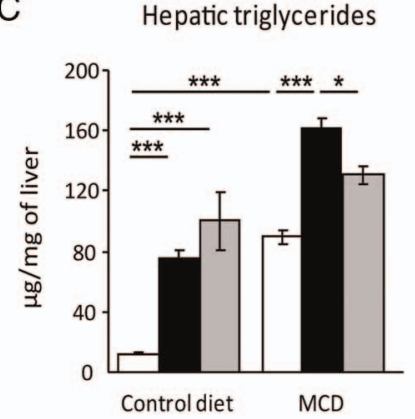

E

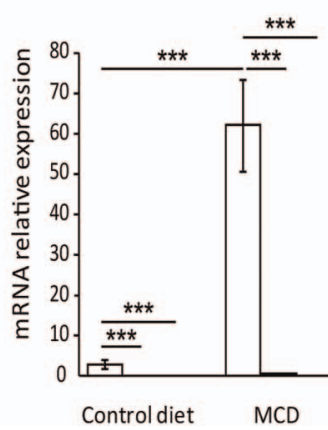

B

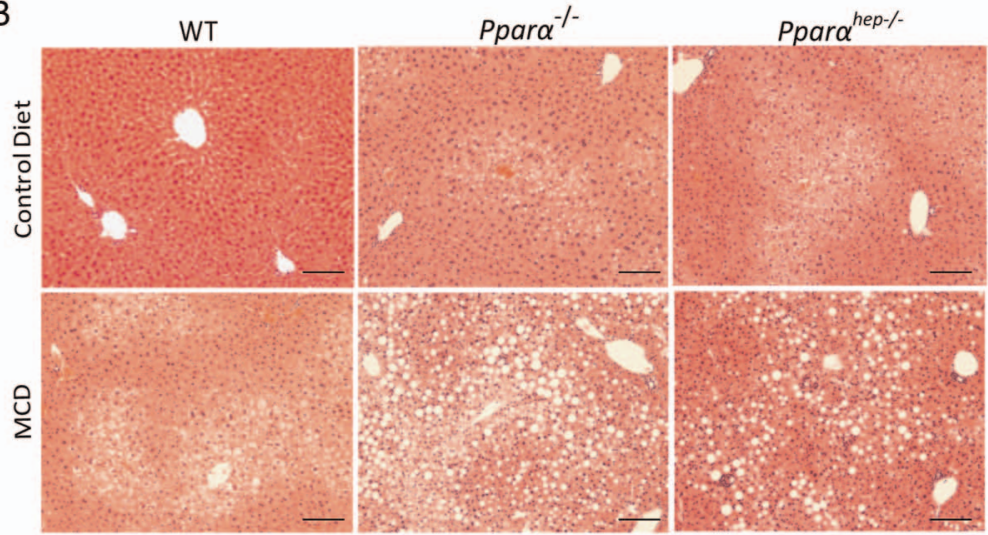

Hepatic cholesterol esters

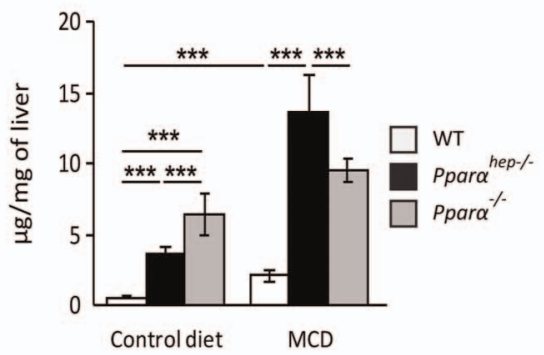

Vnn1

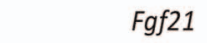

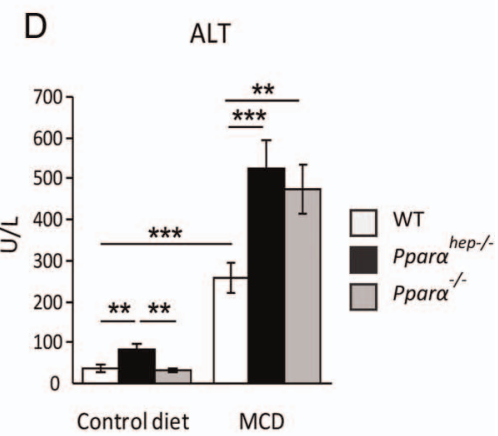

$\mathrm{F}$
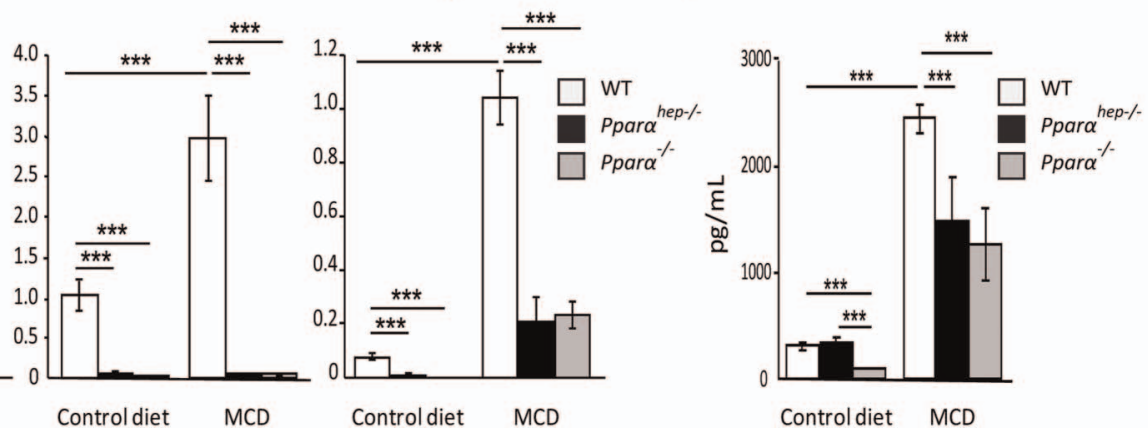

Figure 7 Liver peroxisome proliferator-activated receptor $\alpha$ (PPAR $\alpha)$ deficiency aggravates non-alcoholic steatohepatitis in response to a methionine-deficient and choline-deficient diet (MCD). Wild-type (WT), PPAR $\alpha$ hepatocyte knockout (Ppard ${ }^{\text {hep- }--}$ ) and PPAR $\alpha$ knockout $($ Ppar $\alpha-/-)$ mice were fed a MCD or a control diet for 2 weeks and were killed at ZT8. (A) Body weight gain was measured over 2 weeks. (B) Representative pictures of H\&E staining on liver sections. Scale bar, $100 \mu \mathrm{m}$. (C) Quantification of hepatic triglycerides and cholesterol esters. (D) Alanine transaminase activity level in plasma. (E) Hepatic mRNA expression levels of Cyp4a14, Vnn1 and Fgf21. (F) Plasma levels of fibroblast growth factor 21 (FGF21). Data are shown as mean \pm SEM. ${ }^{*} p \leq 0.05,{ }^{* *} p \leq 0.01,{ }^{* * *} p \leq 0.005$.

linolenic acids in the liver during fasting (see online supplementary file 4), which is in agreement with the fact that both of them are the main fatty acids stored in the white adipose tissues of mice fed a chow diet. ${ }^{36}$ Importantly, we found a high correlation between the kinetics of circulating FFA increase and expression of PPAR $\alpha$ and several of its target genes. Moreover, treatment with a $\beta 3$-adrenergic receptor agonist further enhanced this response in vivo through PPAR $\alpha$ but did not induce detrimental FFA-sensitive response driven by toll-like receptor 4 (TLR4). This is likely due to the mixture of FFA released from the adipose stores. Indeed, fatty acids that accumulated in the liver of Ppara ${ }^{\text {hep-l- }}$ mice during fasting were mostly oleic (C18:1n-9) and linoleic acids (C18:2n-6), and not only saturated fatty acids such as palmitic acid (C16:0). Interestingly, it has been shown that palmitic acid cannot activate TLR4 in the presence of unsaturated FFA. ${ }^{37}$
Overall, our data highlight hepatic PPAR $\alpha$ activity regulation by fatty acids released from adipocytes. This contrasts with the previous evidence that PPAR $\beta / \delta$ rather than PPAR $\alpha$ may act as a FFA sensor. ${ }^{38}$ However, our data support the possibility that this adipose-derived signal is time-restricted and specifically efficient in early night. Moreover, other pathways likely influence PPAR $\alpha$ activity by providing ligands. ${ }^{34} 353940$ Several insulinsensitive signalling mechanisms influence hepatic PPAR $\alpha$, and adipocyte lipolysis is insulin sensitive. ${ }^{41}$ Thus, insulin may coordinate hepatic PPAR $\alpha$, both through cell-autonomous mechanisms and adipocyte lipolysis inducing interorgan communication mediated by FFA release. Our findings also correspond with the recent evidence that adipocyte lipolysis may regulate hepatic Fgf21. ${ }^{42}$ Circulating FGF21 was strictly dependent on hepatocytic PPAR $\alpha$ activation during fasting. Most circulating FGF21 is liver-derived ${ }^{43}$ and Ppara $^{-/-}$mice 
A

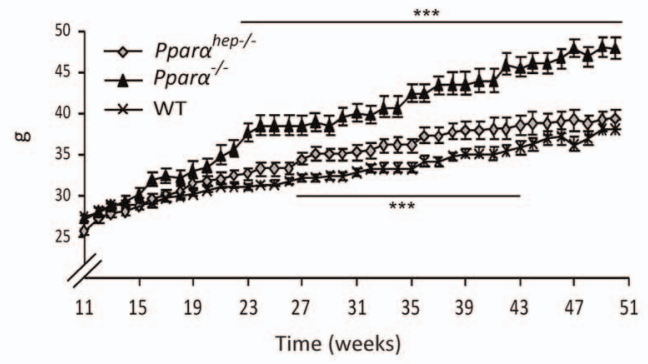

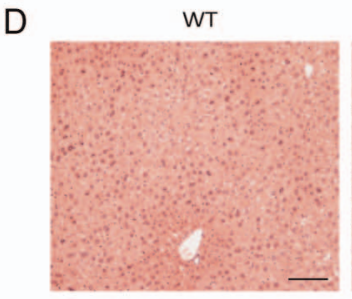

B

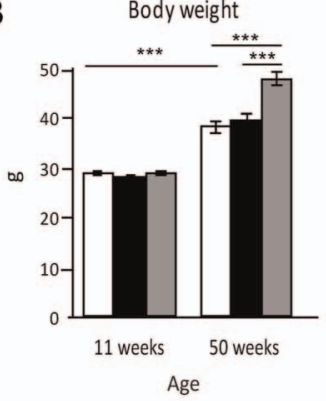

C

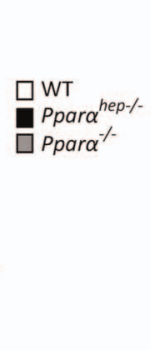

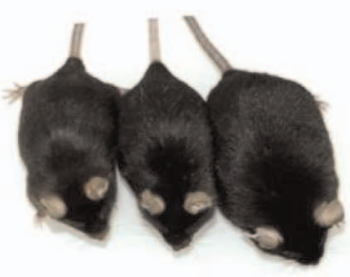

WT

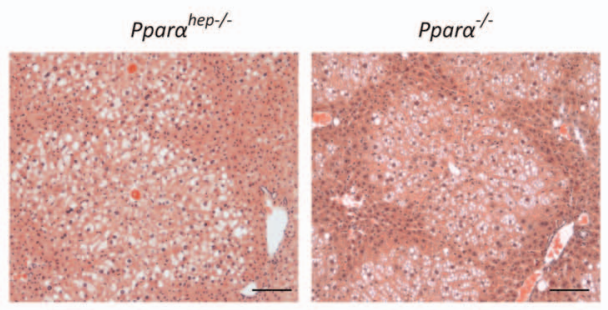

E Hepatictriglycerides Hepaticcholesterol esters
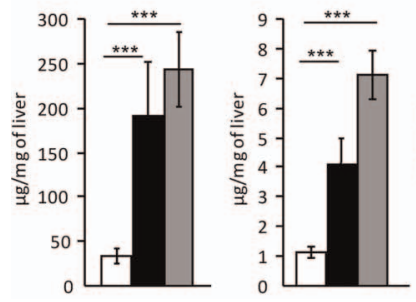

F Plasmacholesterol

Total HDL

Total LDL
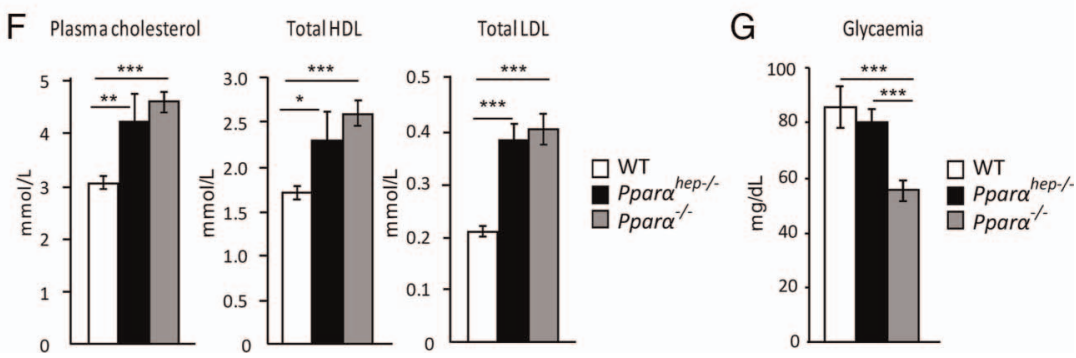

Figure 8 Mice deficient in hepatic peroxisome proliferator-activated receptor $\alpha$ (PPAR $\alpha)$ develop spontaneous hepatic steatosis during ageing. Wild-type (WT), PPAR $\alpha$ hepatocyte knockout $\left(P p a r \alpha^{\text {hep-l-}}{ }^{-}\right.$) and PPAR $\alpha$ knockout $\left(P p a r \alpha^{-I-}\right)$ mice were fed a chow diet for 51 weeks. All mice were killed at ZT16 in a non-fasted state. (A) Body weight gain was followed over time. (B) Comparison of body weight between weeks 11 and 50. (C) Representative pictures of 52-week-old mice of the three genotypes. (D) Representative images of H\&E staining of liver sections. Scale bar, $100 \mu \mathrm{m}$. (E) Quantification of hepatic triglycerides and cholesterol esters. (F) Measurement of plasma total cholesterol, HDL cholesterol and LDL cholesterol.

(G) Fasting glycaemia. Data are shown as mean \pm SEM. ${ }^{*} p \leq 0.05,{ }^{* *} p \leq 0.01,{ }^{* * *} p \leq 0.005$.

show very little FGF21. ${ }^{11} 12$ Other transcription factors can also regulate hepatic Fgf21 expression ${ }^{44-48}$ and PPAR $\alpha$ is also expressed in extrahepatic tissues. ${ }^{13}$ Our findings in Ppard $\phi^{\text {hep-l- }}$ mice showed very little FGF21 without hepatic PPAR $\alpha$ in both fed and fasted states. Ppara ${ }^{-/-}$mice are hypoglycaemic and hypothermic during fasting ${ }^{7}$ and FGF21 is known for its endocrine effect on glucose homeostasis and thermogenesis. ${ }^{13}$ However, compared with fasted Ppara ${ }^{-/-}$mice, fasted Ppara $\alpha^{\text {hep-l- }}$ mice showed reduced hypoglycaemia and hypothermia while FGF21 was equally absent in both models. This indicates that extrahepatocytic PPAR $\alpha$ strongly influenced whole-body glucose homeostasis and temperature independently of hepatocyte PPAR $\alpha$ and FGF21 production during fasting. In addition, while FGF21 prevents steatosis in different mouse models ${ }^{13}{ }^{30}$ and FGF21 reduces hepatic lipids in WT mice, its overexpression is not sufficient to protect from lipid accumulation in Ppara ${ }^{\text {bep-l- }}$ and in Ppara ${ }^{-/}$mice. Therefore, the absence of FGF21 is not the primary cause for the steatosis observed in Ppara ${ }^{\text {bep-l- }}$ mice.

Lack of hepatic PPAR $\alpha$ impairs the liver's ability to use FFA from acute lipolysis, resulting in steatosis. MCD diet-induced weight $\operatorname{loss}^{49} 50$ also correlated with hepatic PPAR $\alpha$ activity, suggesting that chronic lipolysis elevates hepatocytic PPAR $\alpha$ activity in non-fasted mice. In agreement with the findings in wholebody PPAR $\alpha$-deficient mice, ${ }^{20}$ our data demonstrated that the absence of hepatocytic PPAR $\alpha$ was sufficient to increase MCD diet-induced liver damage. FGF21 expression/circulating levels increased in steatohepatitis, supporting the possibility that elevated FGF21 may reflect liver stress without fasting. This MCD diet-induced FGF21 increase was not strictly PPAR $\alpha$-dependent, consistent with the findings that amino acid deprivation induces hepatic FGF21 expression through ATF $4 .{ }^{44}$ PPAR $\alpha$ presence led to greater FGF21 increase, and may contribute to hepatoprotection from lipotoxic lipid accumulation. ${ }^{30}$

MCD diet is widely used for preclinical NASH studies. However, it has many limitations, including the important weight loss that occurs in mice fed such diet. Therefore, we also tested the role of hepatocyte PPAR $\alpha$ in lipid homeostasis in response to a short-term HFD feeding, which is sufficient to initiate early neutral lipid accumulation that may promote NAFLD. Ppard ${ }^{\text {bep-l- }}$ mice showed marked increase in hepatic steatosis in response to 2 weeks of HFD feeding (see online supplementary file 11) suggesting that hepatocyte PPAR $\alpha$ plays a dual role in exogenous (dietary) as well as in endogenous (released from adipocyte lipolysis) fatty acid homeostasis.

Previous studies have shown that Ppard ${ }^{-/-}$mice show a significant alteration of systemic lipid metabolism that leads to hepatic steatosis in ageing mice. Since PPAR $\alpha$ is active in skeletal muscles ${ }^{23}$ adipose tissues, ${ }^{24}{ }^{25}$ intestines, ${ }^{26}$ kidneys ${ }^{27}$ and heart, ${ }^{28}$ which all contribute to fatty acid homeostasis, it is impossible to determine whether the spontaneous steatosis that occurs in ageing $\mathrm{Ppara}^{-/-}$mice originates from a defect in the hepatocytic PPAR $\alpha$ activity. This led us to investigate ageing-related differences between Ppara ${ }^{-/-}$and Pparo $\alpha^{\text {hep-l- }}$ 
Figure 9 Overview of hepatocyte-specific peroxisome proliferator-activated receptor $\alpha$ (PPAR $\alpha$ )-regulated genes involved in fatty acid metabolism. This figure was designed based on transcriptome analysis of PPAR $\alpha$-dependent gene expression in hepatocytes. Genes listed in regular font are induced by fenofibrate and by fasting in wild-type (WT) but not in Ppard ${ }^{\text {hep-/- }}$ mice. Genes in italics are repressed by fenofibrate and by fasting in WT but not in Ppara $\alpha^{\text {hep-l- }}$ mice. Genes referenced in bold are downregulated in Ppard ${ }^{\text {hep-I- }}$ compared with WT mice, whatever the conditions.

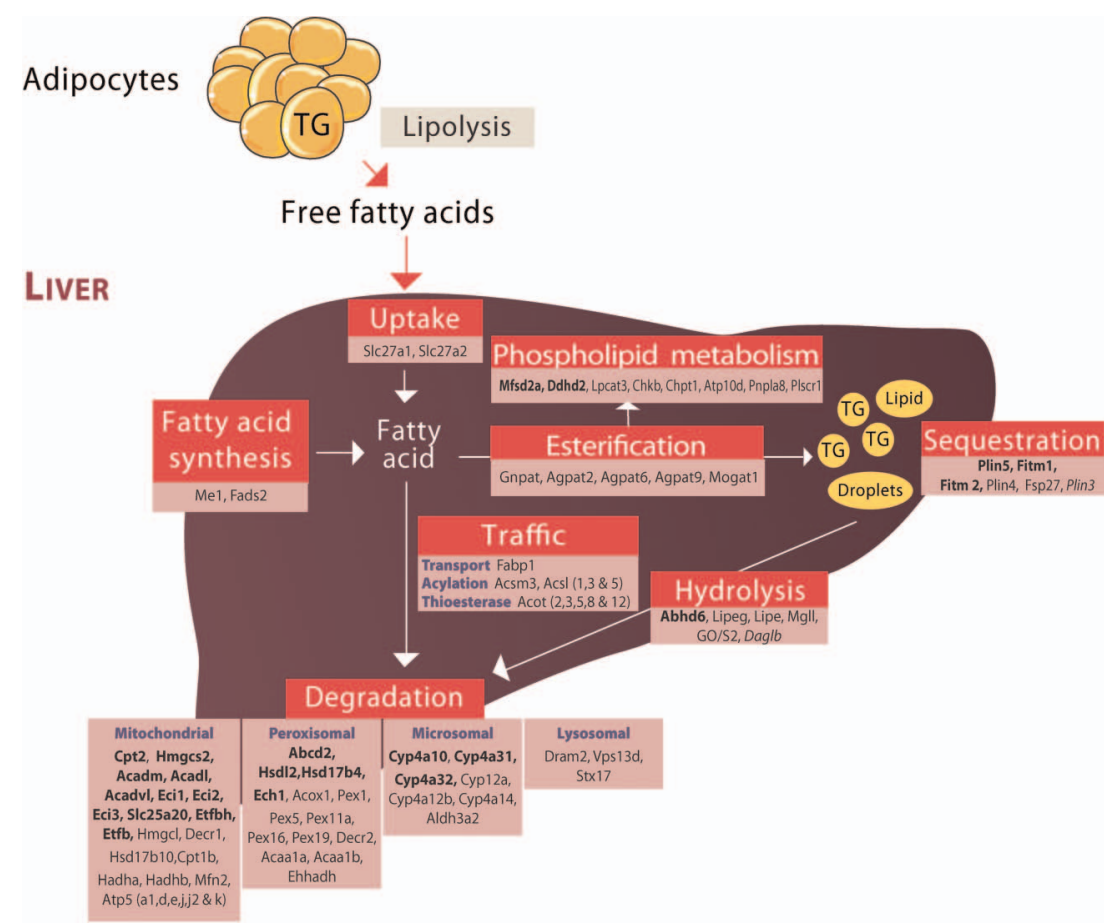

mice. During ageing, Ppara ${ }^{-/}$mice became overweight and developed steatosis, while Ppard ${ }^{\text {hep-/- }}$ mice only suffered steatosis. Therefore, neither obesity nor hyperglycaemia, which are both known to promote NAFLD, ${ }^{15} 16$ is responsible for the steatosis observed in mice with hepatocyte-specific PPAR $\alpha$ deletion.

Furthermore, both Ppard $^{-/-}$and Ppard ${ }^{\text {hep-l- }}$ ageing mice were hypercholesterolaemic. This is likely due to the dysregulation of apolipoproteins gene expression as well as cholesterol transport (Abcg8) as revealed in microarray analysis (see online supplementary file 12A). It is also possible that the cholesterol biosynthesis pathway driven by SREBP-2 may be dysregulated in the absence of PPAR $\alpha$ since some of the SREBP-2 genes are elevated in $P_{p a r \alpha}{ }^{--}$and/or in Ppard ${ }^{\text {hep-l- }}$ mice (see online supplementary file 12B). Therefore, this suggests that drugs that activate hepatocytic PPAR $\alpha$ will likely influence whole-body fatty acid and cholesterol homeostasis.

Altogether, our extensive analysis performed in Ppard ${ }^{\text {hep-l- }}$ mice has allowed us to extend the evidence for the central role of PPAR $\alpha$ in hepatocyte fatty acid homeostasis (figure 9). PPAR $\alpha$ is strikingly essential to many aspects of fatty acid homeostasis including degradation through oxidative pathways. Our work provides the first demonstration that hepatocytespecific PPAR $\alpha$ deletion impairs whole-body fatty acid homeostasis during fasting, MCD and HFD feeding as well as in ageing. These findings underscore the central role of PPAR $\alpha$ in the clearance of dietary fatty acids and of FFA released from adipocytes, the major source of lipid accumulation in NAFLD. These data highlight the relevance of PPAR $\alpha$ as a drug target for NAFLD treatment.

\author{
Author affiliations \\ ${ }^{1}$ INRA UMR1331, ToxAlim, University of Toulouse, Toulouse, France \\ ${ }^{2}$ INSERM UMR 1048, Institute of Metabolic and Cardiovascular Diseases, Toulouse, \\ France \\ ${ }^{3}$ University of Toulouse, UMR1048, Paul Sabatier University, France \\ ${ }^{4}$ INSERM U1016, Cochin Institute, Paris, France \\ ${ }^{5}$ CNRS UMR 8104, Paris, France \\ ${ }^{6}$ University of Paris Descartes, Sorbonne Paris Cité, Paris, France
}

${ }^{7}$ INSERM/UPS-US006/CREFRE, Service d'Histopathologie, CHU Purpan, Toulouse, France

${ }^{8}$ INSERM U855, University of Lyon, Lyon, France

${ }^{9}$ INRA UMR1348 Pegase, Saint-Gilles, France

${ }^{10}$ Agrocampus Ouest, UMR1348 Pegase, Rennes, France

${ }^{11}$ Université Européenne de Bretagne, France

${ }^{12}$ Laboratory of Clinical Biochemistry, Toulouse University Hospitals, Toulouse, France

${ }^{13}$ Lee Kong Chian School of Medicine, Nanyang Technological University, Singapore, Singapore

${ }^{14}$ Center for Integrative Genomics, University of Lausanne, Genopode Building, Lausanne, Switzerland

Acknowledgements We thank all members of the EZOP staff, particularly Colette Bétoulières for her careful and outstanding help from the early start of this project. We thank Aurore Dequesnes and Laurent Monbrun for their excellent work on plasma biochemistry. We thank Christine Salon and Florence Capilla for their excellent work on histology. We thank the staff from the Genotoul: Anexplo, Get-TriX and Metatoul-Lipidomic facilities. The authors wish to thank Professor Daniel Metzger, Professor Pierre Chambon (IGBMC, Illkirch, France) and the staff of the Mouse Clinical Institute (Illkirch, France) for their critical support in this project. We thank Professor Didier Trono (EPFL, Lausanne, Switzerland) for providing us with the Albumin-cre mice. We thank Professor David Mangelsdorf (Howard Hughes Medical Institute, Dallas, TX) and Professor Steven Kliewer (UT Southwestern, Dallas, TX) for providing us with the FGF21-deficient mice. We thank Alice Marmugi and Géraldine Michel for their technical assistance. We thank Professor Bertrand Cariou and Professor Bart Staels for constructive discussions.

Contributors $\mathrm{AM}$ initiated the project, designed experiments, performed experiments, analysed the data and wrote the paper. AP, EF, SD, YL, FL, MR, CL, FB and Al contributed to design experiments, perform experiments and to analyse the data. VB designed and performed a critical experiment. JB-M, TAS, PC and LL provided critical analysis and technical support. SL contributed to analyse the data. GM, FR and TP provided critical materials and contributed to design the project. NL, CP and DL critically contributed to design the project and supervised experiments. WW provided critical reagents, designed the project, analysed the data and wrote the paper. HG designed the project, performed experiments, analysed the data and wrote the paper.

Funding This work was funded by grants from the Human Frontier Science Program (HFSP) (WW), by Start-Up Grants from the Lee Kong Chian School of Medicine, Nanyang Technological University, Singapore (to WW), by SFN (to HG), by ANRs 'Crisalis' (to CP and HG), by 'Obelip' (to DL, CP, AM and HG). DL is a member of the Institut Universitaire de France. AM, DL, WW and HG were supported by Région Midi-Pyrénées.

Competing interests None declared.

Provenance and peer review Not commissioned; externally peer reviewed. 
Data sharing statement Gene expression array raw data are deposited in GEO as indicated in the manuscript.

Open Access This is an Open Access article distributed in accordance with the Creative Commons Attribution Non Commercial (CC BY-NC 4.0) license, which permits others to distribute, remix, adapt, build upon this work non-commercially, and license their derivative works on different terms, provided the original work is properly cited and the use is non-commercial. See: http://creativecommons.org/ licenses/by-nc/4.0/

\section{REFERENCES}

1 Browning JD, Horton JD. Molecular mediators of hepatic steatosis and liver injury. J Clin Invest 2004;114:147-52.

2 Wahli W, Michalik L. PPARs at the crossroads of lipid signaling and inflammation. Trends Endocrinol Metab 2012;23:351-63.

3 Braissant O, Foufelle F, Scotto C, et al. Differential expression of peroxisome proliferator-activated receptors (PPARs): tissue distribution of PPAR-alpha, -beta, and -gamma in the adult rat. Endocrinology 1996;137:354-66.

4 Postic C, Girard J. Contribution of de novo fatty acid synthesis to hepatic steatosis and insulin resistance: lessons from genetically engineered mice. J Clin Invest 2008;118:829-38.

5 Kersten S. Integrated physiology and systems biology of PPAR $\alpha$. Mol Metab 2014;3:354-71.

6 Lee SS, Pineau T, Drago J, et al. Targeted disruption of the alpha isoform of the peroxisome proliferator-activated receptor gene in mice results in abolishment of the pleiotropic effects of peroxisome proliferators. Mol Cell Biol 1995;15:3012-22.

7 Kersten S, Seydoux J, Peters JM, et al. Peroxisome proliferator-activated receptor alpha mediates the adaptive response to fasting. J Clin Invest 1999;103:1489-98.

8 Kroetz DL, Yook P, Costet P, et al. Peroxisome proliferator-activated receptor $\alpha$ controls the hepatic CYP4A induction adaptive response to starvation and diabetes. J Biol Chem 1998;273:31581-9.

9 Patsouris D, Mandard S, Voshol PJ, et al. PPARalpha governs glycerol metabolism. J Clin Invest 2004;114:94-103.

10 Lee JM, Wagner M, Xiao R, et al. Nutrient-sensing nuclear receptors coordinate autophagy. Nature 2014;516:112-15.

11 Badman MK, Pissios P, Kennedy AR, et al. Hepatic fibroblast growth factor 21 is regulated by PPARalpha and is a key mediator of hepatic lipid metabolism in ketotic states. Cell Metab 2007;5:426-37.

12 Inagaki $T$, Dutchak $P$, Zhao $G$, et al. Endocrine regulation of the fasting response by PPARalpha-mediated induction of fibroblast growth factor 21. Cell Metab 2007:5:415-25.

13 Kharitonenkov A, Adams AC. Inventing new medicines: The FGF21 story. Mol Metab 2014;3:221-9.

14 Pawlak M, Lefebvre P, Staels B. Molecular mechanism of PPAR $\alpha$ action and its impact on lipid metabolism, inflammation and fibrosis in non-alcoholic fatty liver disease. J Hepatol 2015;62:720-33.

15 Loomba R, Sanyal AJ. The global NAFLD epidemic. Nat Rev Gastroenterol Hepatol 2013:10:686-90.

16 Wree A, Broderick L, Canbay A, et al. From NAFLD to NASH to cirrhosis-new insights into disease mechanisms. Nat Rev Gastroenterol Hepatol 2013;10:627-36.

17 Donnelly $\mathrm{KL}$, Smith $\mathrm{Cl}$, Schwarzenberg SJ, et al. Sources of fatty acids stored in liver and secreted via lipoproteins in patients with nonalcoholic fatty liver disease. J Clin Invest 2005:115:1343-51.

18 Abdelmegeed MA, Yoo SH, Henderson LE, et al. PPARalpha expression protects male mice from high fat-induced nonalcoholic fatty liver. J Nutr 2011;141:603-10.

19 Costet $\mathrm{P}$, Legendre $\mathrm{C}$, Moreé J, et al. Peroxisome proliferator-activated receptor $\alpha$-isoform deficiency leads to progressive dyslipidemia with sexually dimorphic obesity and steatosis. J Biol Chem 1998;273:29577-85.

20 Ip E, Farrell GC, Robertson G, et al. Central role of PPARalpha-dependent hepatic lipid turnover in dietary steatohepatitis in mice. Hepatology 2003;38:123-32.

21 Staels B, Rubenstrunk A, Noel B, et al. Hepatoprotective effects of the dual peroxisome proliferator-activated receptor alpha/delta agonist, GFT505, in rodent models of nonalcoholic fatty liver disease/nonalcoholic steatohepatitis. Hepatology 2013:58:1941-52.

22 Francque $\mathrm{S}$, Verrijken A, Caron S, et al. PPAR $\alpha$ gene expression correlates with severity and histological treatment response in patients with non-alcoholic steatohepatitis. J Hepatol 2015;63:164-73.

23 Liu S, Brown JD, Stanya KJ, et al. A diurnal serum lipid integrates hepatic lipogenesis and peripheral fatty acid use. Nature 2013;502:550-4.

24 Goto T, Lee JY, Teraminami A, et al. Activation of peroxisome proliferator-activated receptor-alpha stimulates both differentiation and fatty acid oxidation in adipocytes. J Lipid Res 2011;52:873-84.

25 Tsuchida A, Yamauchi T, Takekawa S, et al. Peroxisome proliferator-activated receptor (PPAR) $\alpha$ activation increases adiponectin receptors and reduces obesity-related inflammation in adipose tissue: comparison of activation of PPAR $\alpha$, PPAR $\gamma$, and their combination. Diabetes 2005;54:3358-70.

26 Bünger M, van den Bosch HM, van der Meijde J, et al. Genome-wide analysis of PPARalpha activation in murine small intestine. Physiol Genomics 2007;30:192-204.

27 Sugden MC, Bulmer K, Gibbons GF, et al. Role of peroxisome proliferator-activated receptor-alpha in the mechanism underlying changes in renal pyruvate dehydrogenase kinase isoform 4 protein expression in starvation and after refeeding. Arch Biochem Biophys 2001;395:246-52.

28 Haemmerle G, Moustafa T, Woelkart G, et al. ATGL-mediated fat catabolism regulates cardiac mitochondrial function via PPAR- $\alpha$ and PGC-1. Nat Med 2011:17:1076-85.

29 Gentleman RC, Carey VJ, Bates DM, et al. Bioconductor: open software development for computational biology and bioinformatics. Genome Biol 2004;5: R80.

30 Fisher FM, Chui PC, Nasser IA, et al. Fibroblast growth factor 21 limits lipotoxicity by promoting hepatic fatty acid activation in mice on methionine and choline-deficient diets. Gastroenterology 2014;147:1073-83.e6.

31 Cotter DG, Ercal B, Huang $X$, et al. Ketogenesis prevents diet-induced fatty liver injury and hyperglycemia. J Clin Invest 2014;124:5175-90.

32 Hegardt FG. Transcriptional regulation of mitochondrial HMG-CoA synthase in the control of ketogenesis. Biochimie 1998;80:803-6.

33 Sahebkar A, Chew GT, Watts GF. New peroxisome proliferator-activated receptor agonists: potential treatments for atherogenic dyslipidemia and non-alcoholic fatty liver disease. Expert Opin Pharmacother 2014;15:493-503.

34 Chakravarthy MV, Lodhi IJ, Yin L, et al. Identification of a physiologically relevant endogenous ligand for PPARalpha in liver. Cell 2009;138:476-88.

35 Chakravarthy MV, Pan Z, Zhu Y, et al. "New" hepatic fat activates PPARalpha to maintain glucose, lipid, and cholesterol homeostasis. Cell Metab 2005; 1:309-22.

36 Chen W, Zhou H, Liu S, et al. Altered lipid metabolism in residual white adipose tissues of Bscl2 deficient mice. PLOS ONE 2013:8:e82526.

37 Caspar-Bauguil S, Kolditz Cl, Lefort C, et al. Fatty acids from fat cell lipolysis do not activate an inflammatory response but are stored as triacylglycerols in adipose tissue macrophages. Diabetologia 2015;58:2627-36.

38 Sanderson LM, Degenhardt T, Koppen A, et al. Peroxisome proliferator-activated receptor beta/delta (PPARbeta/delta) but not PPARalpha serves as a plasma free fatty acid sensor in liver. Mol Cell Biol 2009;29:6257-67.

39 Jha P, Claudel T, Baghdasaryan A, et al. Role of adipose triglyceride lipase (PNPLA2) in protection from hepatic inflammation in mouse models of steatohepatitis and endotoxemia. Hepatology 2014;59:858-69.

40 Ziouzenkova O, Perrey S, Asatryan L, et al. Lipolysis of triglyceride-rich lipoproteins generates PPAR ligands: evidence for an antiinflammatory role for lipoprotein lipase. Proc Natl Acad Sci USA 2003:100:2730-5.

41 Jo YS, Ryu D, Maida A, et al. Phosphorylation of the nuclear receptor corepressor 1 by protein kinase $B$ switches its corepressor targets in the liver in mice. Hepatology 2015;62:1606-18.

42 Jaeger D, Schoiswohl G, Hofer $P$, et al. Fasting-induced G0/G1 switch gene 2 and FGF21 expression in the liver are under regulation of adipose tissue derived fatty acids. J Hepatol 2015;63:437-45.

43 Markan KR, Naber MC, Ameka MK, et al. Circulating FGF21 is liver derived and enhances glucose uptake during refeeding and overfeeding. Diabetes 2014:63:4057-63.

44 De Sousa-Coelho AL, Marrero PF, Haro D. Activating transcription factor 4-dependent induction of FGF21 during amino acid deprivation. Biochem J 2012;443:165-71.

45 lizuka K, Takeda J, Horikawa Y. Glucose induces FGF21 mRNA expression through ChREBP activation in rat hepatocytes. FEBS Lett 2009;583: 2882-6.

$46 \operatorname{Kim~H}$, Mendez R, Zheng Z, et al. Liver-enriched transcription factor CREBH interacts with peroxisome proliferator-activated receptor $\alpha$ to regulate metabolic hormone FGF21. Endocrinology 2014;155:769-82.

47 Lu P, Yan J, Liu K, et al. Activation of aryl hydrocarbon receptor dissociates fatty liver from insulin resistance by inducing fibroblast growth factor 21. Hepatology 2015;61:1908-19.

48 Uebanso $T$, Taketani $Y$, Yamamoto $H$, et al. Liver $X$ receptor negatively regulates fibroblast growth factor 21 in the fatty liver induced by cholesterol-enriched diet. J Nutr Biochem 2012;23:785-90.

49 Tanaka N, Takahashi S, Fang ZZ, et al. Role of white adipose lipolysis in the development of NASH induced by methionine- and choline-deficient diet. Biochim Biophys Acta 2014;1841:1596-607.

50 Jha $\mathrm{P}$, Knopf $\mathrm{A}$, Koefeler $\mathrm{H}$, et al. Role of adipose tissue in methionine-choline-deficient model of non-alcoholic steatohepatitis (NASH). Biochim Biophys Acta 2014;1842:959-70. 